\title{
Deciphering molecular mechanisms underlying chemoresistance in relapsed AML patients: towards precision medicine overcoming drug resistance
}

\author{
May Levin ${ }^{1}$, Michal Stark ${ }^{1}$, Yishai Ofran ${ }^{2^{*}}$ and Yehuda G. Assaraf ${ }^{*^{*}}$
}

\begin{abstract}
Background: Acute myeloid leukemia (AML) remains a devastating disease with a 5-year survival rate of less than $30 \%$. AML treatment has undergone significant changes in recent years, incorporating novel targeted therapies along with improvements in allogeneic bone marrow transplantation techniques. However, the standard of care remains cytarabine and anthracyclines, and the primary hindrance towards curative treatment is the frequent emergence of intrinsic and acquired anticancer drug resistance. In this respect, patients presenting with chemoresistant AML face dismal prognosis even with most advanced therapies. Herein, we aimed to explore the potential implementation of the characterization of chemoresistance mechanisms in individual AML patients towards efficacious personalized medicine.

Methods: Towards the identification of tailored treatments for individual patients, we herein present the cases of relapsed AML patients, and compare them to patients displaying durable remissions following the same chemotherapeutic induction treatment. We quantified the expression levels of specific genes mediating drug transport and metabolism, nucleotide biosynthesis, and apoptosis, in order to decipher the molecular mechanisms underlying intrinsic and/or acquired chemoresistance modalities in relapsed patients. This was achieved by real-time PCR using patient cDNA, and could be readily implemented in the clinical setting.
\end{abstract}

Results: This analysis revealed pre-existing differences in gene expression levels between the relapsed patients and patients with lasting remissions, as well as drug-induced alterations at different relapse stages compared to diagnosis. Each of the relapsed patients displayed unique chemoresistance mechanisms following similar treatment protocols, which could have been missed in a large study aimed at identifying common drug resistance determinants.

Conclusions: Our findings emphasize the need for standardized evaluation of key drug transport and metabolism genes as an integral component of routine AML management, thereby allowing for the selection of treatments of choice for individual patients. This approach could facilitate the design of efficacious personalized treatment regimens, thereby reducing relapse rates of therapy refractory disease.

\footnotetext{
*Correspondence: y_ofran@rambam.health.gov.il; assaraf@technion.ac.il

${ }^{1}$ The Fred Wyszkowski Cancer Research Laboratory, Dept. of Biology,

Technion-Israel Institute of Technology, 3200003 Haifa, Israel

${ }^{2}$ Department of Hematology and Bone Marrow Transplantation,

Rambam Health Care Campus, Haifa, Israel
}

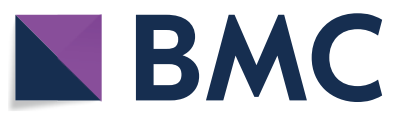

(c) The Author(s) 2021. This article is licensed under a Creative Commons Attribution 4.0 International License, which permits use, sharing, adaptation, distribution and reproduction in any medium or format, as long as you give appropriate credit to the original author(s) and the source, provide a link to the Creative Commons licence, and indicate if changes were made. The images or other third party material in this article are included in the article's Creative Commons licence, unless indicated otherwise in a credit line to the material. If material is not included in the article's Creative Commons licence and your intended use is not permitted by statutory regulation or exceeds the permitted use, you will need to obtain permission directly from the copyright holder. To view a copy of this licence, visit http://creativeco mmons.org/licenses/by/4.0/. The Creative Commons Public Domain Dedication waiver (http://creativecommons.org/publicdomain/ zero/1.0/) applies to the data made available in this article, unless otherwise stated in a credit line to the data. 
Keywords: AML, Chemotherapy, Intrinsic/acquired chemoresistance, Resistance modalities, Drug metabolism, Relapse, Precision medicine

\section{Background}

Acute myeloid leukemia (AML) is a heterogeneous disease originating from early precursors of the myeloid hematopoietic cell lineage [1,2]. While no new drugs were approved for AML treatment in almost 50 years, the FDA granted approval to eight novel agents for various AML indications in the last three years [3]. However, some of these agents target specific mutations that present only in a limited subset of AML patients, and traditional intensive protocols remain the therapy of choice for most AML patients [4]. Moreover, even with this torrent of new therapeutic agents, prognosis of AML patients remains dismal with 5 -year survival rates $<30 \%[5,6]$. The leading cause of AML-related mortality remains treatment failure due to refractory or relapsed disease, resulting from chemotherapy resistance [7]. Standard AML induction regimens mainly comprise of cytarabine (cytosine arabinoside, Ara-C) and daunorubicin (DNR), followed by high dose cytarabine consolidation. Common treatment protocols for relapsed AML may include mitoxantrone (MX) or fludarabine and etoposide (VP16) [8]. However, in most cases high dose cytarabine is also administered. Since the efficacy of these cytotoxic drugs relies on their interaction with specific intracellular targets (Table 1 and Additional file 1: Figure S1), many drug resistance mechanisms emerge which are associated with alterations in drug transport and metabolism. These include, for example, decreased cellular accumulation due to impaired drug uptake and/or enhanced drug efflux predominantly via ATP-binding cassette $(A B C)$ efflux transporters [9-17], loss of metabolic activation of a prodrug [11, 17-23], enhanced drug degradation [17, 24], qualitative and quantitative alterations in the target enzymes [25-28], as well as drug sequestration [29].

Ara- $C$ is a nucleoside analogue pro-drug, whose active metabolite Ara-CTP blocks DNA polymerases, hence disrupting DNA replication [30]. Ara-C can be taken up into cells via several transport systems including the equilibrative nucleoside transporter 1 (ENT1, SLC29A1) [13], the concentrative $\mathrm{Na}^{+}$-nucleoside cotransporter 3 (CNT3, SLC28A3) [31], and the organic cation transporter, novel, type 1 (OCTN1, SLC22A4) [32]. Thereafter, Ara-C is sequentially phosphorylated to Ara-CTP by deoxycytidine kinase (dCK), deoxycytidylate kinase (dCMPK), and finally by nucleotide diphosphate kinase (NDK) [30]. Accordingly, commonly reported Ara-C resistance mechanisms include downregulation of ENT1 [11,33-35] or CNT3 [36], loss of function of dCK [21, 34, $35,37-42]$, or upregulation of the catabolic enzymes cytidine deaminase (CDA) and deoxycytidine monophosphate deaminase (dCMPD) [17, 24, 43]. Unlike other chemotherapeutic agents, enhanced Ara-C efflux is not an established mechanism of drug resistance.

DNR, MX and VP-16 are amphipathic topoisomerase II inhibitors which enter the cell via passive diffusion using a membrane flip-flop mechanism [44]. Therefore,

Table 1 Properties of the chemotherapeutic drugs used in AML

\begin{tabular}{|c|c|c|c|c|c|}
\hline Drug & Target & Influx & Metabolism $^{a}$ & Efflux & Refs. \\
\hline Cytarabine (Ara-C) & DNA polymerases & ENT1, CNT3, OCTN1 & $\begin{array}{l}\text { Activation: dCK, dCMPK, } \\
\text { NDK. Inactivation: CDA, } \\
\text { dCMPD, PN-I. }\end{array}$ & MRP4,7,8 & {$[14,30-33,78-80]$} \\
\hline Daunorubicin (DNR) & DNA, Topoisomerase ॥ & Passive diffusion & & P-gp, MRP1,7, BCRP & {$[44,51,81-84]$} \\
\hline Mitoxantrone (MX) & DNA, Topoisomerase ॥ & Passive diffusion & & P-gp, MRP1, BCRP & {$[44,85-90]$} \\
\hline Etoposide (VP-16) & Topoisomerase II & Passive diffusion & & P-gp, MRP1-3,6, BCRP & {$[16,91,92]$} \\
\hline Methotrexate (MTX) & DHFR, TS, AICARFT & RFC, PCFT & $\begin{array}{l}\text { Aldehyde oxidase, FPGS } \\
\text { (polyglutamylation) }\end{array}$ & P-gp, MRP1-5, BCRP & {$[16,93,94]$} \\
\hline Venetoclax (VEN) & $\mathrm{BCl}-2$ & Passive diffusion & & $P-g p$ & {$[72,95]$} \\
\hline $\begin{array}{l}\text { Gemtuzumab Ozogamicin } \\
\text { (GO) }\end{array}$ & DNA & Ab-mediated endocytosis & $\begin{array}{l}\text { Lysosomal Calicheam- } \\
\text { icin cleavage from Ab, } \\
\text { glutathione }\end{array}$ & P-gp, MRP1 & {$[73,77]$} \\
\hline
\end{tabular}

DHFR, dihydrofolate reductase; TS, thymidylate synthase; AICARFT, aminoimidazole-4-carboxamide ribonucleotide formyltransferase; Bcl-2, B-cell leukemia/ lymphoma 2; ENT1, equilibrative nucleoside transporter 1; CNT3, concentrative nucleoside transporter 3; OCTN1, organic cation transporter, novel, type 1; RFC, reduced folate carrier; PCFT, proton coupled folate transporter; dCK, deoxycytidine kinase; dCMPK, deoxycytidylate kinase; NDK, nucleoside diphosphate kinase; CDA, cytidine deaminase; dCMPD, deoxycytidylate deaminase; PN-I, cytosolic 5-nuleotidase 3A; FPGS, folylpoly- $y$-glutamate synthetase; MRP, multidrug resistanceassociated protein; P-gp, P-glycoprotein; BCRP, breast cancer resistance protein.

a Occuring in leukemic cells. 
the main determinants affecting DNR, MX or VP-16 resistance are genetic alterations in their target enzymes [25-27, 45-48] as well as increased activity of their efflux transporters, mainly P-glycoprotein (P-gp, ABCB1) $[27,47,49-54]$. Due to their lysosomotropic nature (i.e. hydrophobic weak bases), an established mechanism of resistance to all three drugs is lysosomal sequestration [55-57] which entraps these drugs away from their nuclear targets and enhances their extrusion from the cell via lysosomal exocytosis [58].

Apart from these modalities, cells may also acquire multidrug resistance (MDR) to various cytotoxic agents by acquiring resistance to apoptosis [59-63]. In this respect, a recent important addition to the armamentarium of AML treatment protocols is venetoclax (VEN), an inhibitor of the apoptosis regulator Bcl-2 [63]. VEN is currently administered in the initial induction in combination with hypomethylating agents in patients which are unfit for intensive chemotherapy [64, 65]; this combination is also effective in relapsed AML [66]. Clinical trials are underway to assess the combination of VEN with intensive chemotherapy. Resistance to VEN might result from an increase in other anti-apoptotic proteins, including the induced myeloid leukemia cell differentiation protein Mcl-1 or Bcl-XL [67-70], loss of the pro-apoptotic BAX [71], and possibly drug efflux via P-gp [72]. While VEN was initially discovered and used in distinct types of hematological cancers, other novel treatments were designed to specifically target AML [4]. In this respect, gemtuzumab ozogamicin (GO, Mylotarg) is an antibody-drug conjugate comprising an $\alpha$-CD33 monoclonal antibody and a derivative of the anti-tumor antibiotic calicheamicin- $\gamma 1[73,74]$. This conjugate enters cells via receptor-mediated endocytosis; thereafter, calicheamicin is cleaved from the antibody in the acidic lysosomal lumen and diffuses to the nucleus where it binds to DNA and inflicts strand scission [75]. GO treatment is effective in some relapsed AML patients, but treatment failure and subsequent relapse pose formidable obstacles $[73,74,76]$, as GO is a substrate of the MDR efflux transporters P-gp and multidrug resistance-associated protein 1 (MRP1, ABCC1) $[74,76,77]$.

The current paper focuses on two young AML patients who relapsed following chemotherapy and hematopoietic stem cell transplantation (HSCT). The paper describes their treatment course and clinical responses, and pinpoints the molecular mechanisms underlying chemoresistance. Evaluation of the patients' mRNA expression levels of specific drug transport, drug metabolism, nucleotide biosynthesis, and apoptosis genes at different retrospective stages of their disease, revealed pre-existing alterations compared to AML patients displaying lasting remissions following the same induction chemotherapy protocol. This study also uncovered alterations at the relapse stages when compared to diagnosis, which plausibly conferred drug resistance. These findings emphasize the need for standardized evaluation of key drug transport and metabolism genes as part of the routine AML management, in order to design personalized treatment regimens, thereby reducing the emergence of relapsed and/or refractory disease.

\section{Methods \\ Patient specimens}

Adult AML patient specimens studied in the current paper were derived as part of the routine clinical management at the Rambam Health Care Campus (Haifa, Israel). The use of the samples was approved by the IRB committee (study number RMB 076-15) following informed consent by the patients in accordance with the Declaration of Helsinki. White blood cells (WBC) were isolated from peripheral blood or from bone marrow aspiration by Lymphoprep (STEMCELL Technologies, Vancouver, Canada) density gradient centrifugation. The resultant WBC were processed immediately for RNA isolation, or cryopreserved in RPMI-1640 medium (Gibco, Life Technologies, Grand Isle, NY) containing 40\% fetal bovine serum and 10\% DMSO until analysis. The gene expression levels in the subjects of this report (i.e. P1 and P2, Table 2 and Fig. 1 and 7, respectively) were compared to five bone marrow specimens from "good response" (GR) AML patients, i.e. GR1-5, displaying durable remissions following drug treatment with the same induction protocol (Table 2). Notably, the control patients were either of different age or sex compared to P1 and P2, which could be a limitation; however, we focused on comparing genes that directly impact the treatment outcome of specific drugs, regardless of patient age or sex.

\section{RNA purification and CDNA synthesis}

WBC were centrifuged at $800 \mathrm{xg}$ for $3 \mathrm{~min}$ and washed twice with PBS. RNA was isolated using TRI Reagent according to the instructions of the manufacturer (Sigma Aldrich, St. Louis, MO, USA). One $\mu$ g RNA was used for cDNA synthesis using the high capacity cDNA reverse transcription kit according to the manufacturer's instructions (Thermo Fisher Scientific, Waltham, MA, USA).

\section{Quantitative Real-Time (RT) polymerase chain reaction (PCR)}

RT-PCR was performed in triplicates with the perfeCTa SYBR Green SuperMix (Quanta bio, Beverly, MA, USA) using $150 \mathrm{nM}$ forward and reverse oligonucleotide primers (Table 3 ) and $0.25 \mathrm{ng} / \mu \mathrm{l} \mathrm{cDNA}$ per reaction. Gene expression levels were normalized to glucuronidase $\beta$ (GUSB) that was used as an internal 
Table 2 Patient details

\begin{tabular}{|c|c|c|c|c|c|c|c|c|c|}
\hline & Age & Sex & Diagnosis & $\begin{array}{l}\text { Karyotype/ } \\
\text { Mutations }\end{array}$ & ELN risk score & WHO AML category & $\begin{array}{l}\text { De-Novo/ } \\
\text { secondary } \\
\text { AML }\end{array}$ & WBC at diagnosis & $\begin{array}{l}\text { Extramedullary } \\
\text { involvement }\end{array}$ \\
\hline P1 & 27 & Female & Jan 2019 & $\begin{array}{l}\text { T }(10 ; 11)(p 11 ; q 11) \\
\text { del }(9)(q 13 q 22)[3] / \\
\text { Normal }[17]\end{array}$ & Intermediate & $\begin{array}{l}\text { M4 - acute mono- } \\
\text { blastic/ monocytic } \\
\text { leukemia }\end{array}$ & Denovo & $1.24 \times 1000 / \mathrm{mcl}$ & No \\
\hline P2 & 18 & Female & Dec 2017 & $t(8 ; 21)$ & Favorable & $\begin{array}{l}\text { M1- AML without } \\
\text { maturation }\end{array}$ & Denovo & $3.05 \times 1000 / \mathrm{mcl}$ & No \\
\hline GR1 & 38 & Male & May 2016 & $\begin{array}{l}\text { Normal Karyotype, } \\
\text { NPM1 mut }\end{array}$ & Favorable & $\begin{array}{l}\text { M2- AML with matu- } \\
\text { ration }\end{array}$ & Denovo & $166 \times 1000 / \mathrm{mcl}$ & No \\
\hline GR2 & 62 & Male & Sep 2018 & $\begin{array}{l}\text { Normal Karyotype, } \\
\text { NPM1 } 1^{\text {mut }}\end{array}$ & Favorable & $\begin{array}{l}\text { M1- AML without } \\
\text { maturation }\end{array}$ & Denovo & $6.6 \times 1000 / \mathrm{mcl}$ & No \\
\hline GR3 & 69 & Male & Jan 2017 & Normal Karyotype & Intermediate & $\begin{array}{l}\text { M2- AML with matu- } \\
\text { ration }\end{array}$ & Denovo & $11.7 \times 1000 / \mathrm{mcl}$ & No \\
\hline GR4 & 63 & Female & Dec 2010 & Normal Karyotype & Intermediate & $\begin{array}{l}\text { M1- AML without } \\
\text { maturation }\end{array}$ & Denovo & $4.4 \times 1000 / \mathrm{mcl}$ & No \\
\hline GR5 & 28 & Male & Oct 2013 & $\mathrm{t}(8 ; 21)$ & Favorable & $\begin{array}{l}\text { M2- AML with matu- } \\
\text { ration }\end{array}$ & Denovo & $25.8 \times 1000 / \mathrm{mcl}$ & No \\
\hline
\end{tabular}

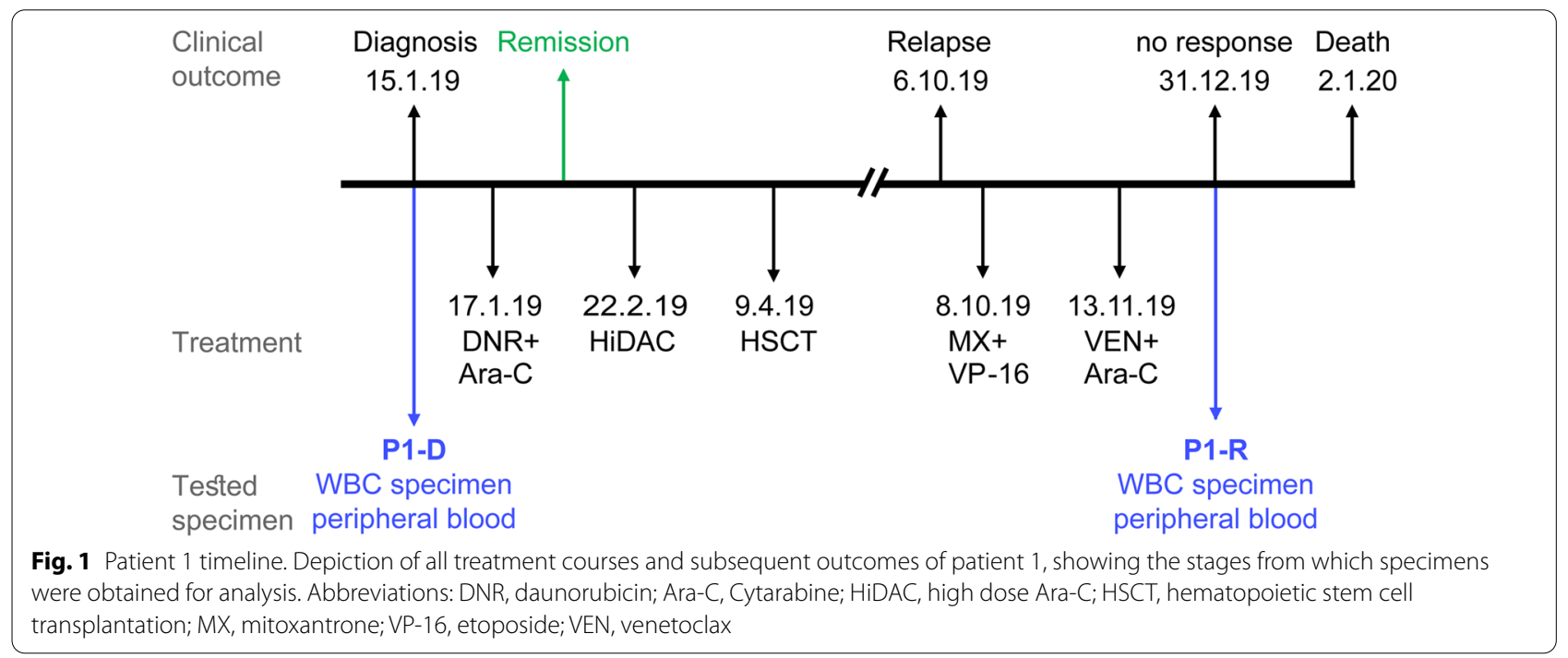

control. RT-PCR reactions were performed using the 7300 Real-Time PCR System, and results were analyzed with the 7300-system sequence detection software version 1.4 (Applied Biosystems, CA, USA).

\section{Correlation of gene expression and overall survival in AML}

Correlation between gene expression levels and overall survival (OS) in AML patients was calculated and plotted using the GEPIA2 server [100]. The analysis was set to quartile cutoff and gene expression levels were normalized to DNA-directed RNA polymerase I subunit D (POLR1D).

\section{Results and discussion \\ Patient 1}

Patient 1 (P1), which was diagnosed with AML on January 15th, 2019 (Fig. 1, Table 2), presented with a karyotype containing the translocation $\mathrm{t}(10 ; 11)(\mathrm{p} 11 ; \mathrm{q} 11)$ and the deletion $\operatorname{del}(9)(\mathrm{q} 13 \mathrm{q} 22)$ in $15 \%(3 / 20)$ of cells. She received standard induction chemotherapy of Ara-C (7 days, $100 \mathrm{mg} / \mathrm{m}^{2}$ ) and DNR (3 days, $90 \mathrm{mg} / \mathrm{m}^{2}$ ) which resulted in remission. This was followed by consolidation with high dose Ara-C (HiDAC, $3 \mathrm{~g} / \mathrm{m}^{2}, 6$ doses). The patient underwent allogeneic HSCT while in complete remission (CR) 1, but relapsed six months later. A salvage protocol of MX (2 days, $30 \mathrm{mg} / \mathrm{m}^{2}$ ) and VP-16 (5 days, 
Table 3 RT-PCR primers

\begin{tabular}{|c|c|c|c|c|}
\hline Gene & Forward primer sequence & Reverse primer sequence & Refs. & Refseq accession \\
\hline ENT1 & GGGCAGCCTGTTTGGTCT & CCACTGGCAATAGCGCAG & [96] & NM_001078177.2 \\
\hline ENT2 & CTCCTGTCCATGGCCAGTG & GGGCCTGGGATGATTTATTG & [96] & NM_001300868.1 \\
\hline ENT3 & TCAGCGGTGCCTCCACTGT & GCAGCCAAGTCCACCAATGA & [96] & NM_018344.6 \\
\hline CNT3 & ACATTTCTTTTGGGGTTCCAT & GCAATCAGATTCACAGCGATG & [96] & NM_001199633.2 \\
\hline $\mathrm{dCK}$ & GCCGCCACAAGACTAAGGAA & GACTTCCCTGCAGCGATGTT & [42] & NM_000788.3 \\
\hline CDA & TGTGCTGAACGGACCGCTA & GCAGGTCCTCAGGCCCAA & {$[42]$} & NM_001785 \\
\hline NDK & ATTCCGCCTTGTTGGTCTGA & TTGGAGTCTGCAGGGTTGGT & Current & NM_198175 \\
\hline PN-I & AACAACATAGCATCCCCGTGT & TTCCTCAAGGCACCATCATGT & Current & NM_001002010.5 \\
\hline BCRP & GGATGAGCCTACAACTGGCTT & CTTCCTGAGGCCAATAAGGTG & {$[97]$} & NM_004827.3 \\
\hline MRP1 & GTGTTTCTGGTCAGCCCAACT & TTGGATCTCAGGATGGCTAGG & [97] & NM_004996 \\
\hline P-gp & CCGACTTACAGATGATGTCTCCAA & CAGACAGCAGCTGACAGTCCAA & Current & NM_000927 \\
\hline $\mathrm{BCL} 2$ & GTCATGTGTGTGGAGAGCGTCA & GGCAGGCATGTTGACTTCACTT & Current & NM_000633 \\
\hline$B C L X(L)$ & TCTTCCGGGATGGGGTAAAC & AAGCGTTCCTGGCCCTTTC & Current & NM_138578 \\
\hline MCL1 & GGACAAAACGGGACTGGCTAG & TGGCTAGGTTGCTAGGGTGC & Current & NM_021960 \\
\hline CTSD & TGCTCAAGAACTACATGGACGC & CGAAGACGACTGTGAAGCACT & [98] & NM_001909 \\
\hline ATP6V1H & AGCCCTGAAGAGAAGCAAGAGA & CGATTCAACATTGGCAGAAAGT & [98] & NM_015941 \\
\hline MSMO1 & AGCATCCTTGGCTGTGGAATAT & CCCATGTCTCTGGCTTATCCTT & Current & NM_006745 \\
\hline HMGCR & GGGAAAATATTGCTCGTGGAAT & CAAGGACACACAAGCTGGGAA & Current & NM_000859.3 \\
\hline CAD & GGTCTCTGCAAGTGGTTTGAA & CCTGTTCCCGCAACTTCTT & [96] & NM_004341 \\
\hline CTPS & CCCCAGATCTGGTTGTATGCA & AAGCGATCATATCTGTCAGCCA & Current & NM_001905 \\
\hline UMPS & GGATTATGGAACTAAGCGTCTTGT & CACACTGAGTGGAGGCGGAT & Current & NM_000373 \\
\hline GART & GTGGAGGAAGGGAACATACGC & TCTCTTTGCAGAATTGAGCAAGG & [99] & NM_000819 \\
\hline TS & TCCCGAGACTTTTTTGGACAGC & TGATGGTGTCAATCACTCTTTGC & [99] & NM_001071 \\
\hline DHFR & ATGCCTTAAAACTTACTGAACAACCA & TGGGTGATTCATGGCTTCCT & [99] & NM_000791 \\
\hline RFC & ACCATCATCACTTTCATTGTCTC & ATGGACAGGATCAGGAAGTACA & [99] & NM_194255 \\
\hline FPGS & GAGAGGCCGAGCGGTGG & TGCCTGTGGATGACACCTCTG & Current & NM_004957 \\
\hline GUSB & CCATTCCTATGCCATCGTG & ATGTCGGCCTCGAAGGG & [96] & NM_000181 \\
\hline
\end{tabular}

$100 \mathrm{mg} / \mathrm{m}^{2}$ ) was administrated with no response. Thus, subcutaneous low dose Ara-C (10 days, $\left.20 \mathrm{mg} / \mathrm{m}^{2}\right)$ and VEN (1 day, $600 \mathrm{mg}$ ) were prescribed. Following treatment, the patient suffered from severe leukopenia, developed sepsis and succumbed to her disease within less than a year from diagnosis.

To identify the molecular mechanisms underlying treatment failure in $\mathrm{P} 1$, we performed a retrospective gene expression analysis on two WBC specimens from this patient: one from the time of diagnosis (i.e. 15.1.19, P1-D) and another post-treatment sample after the relapse (i.e. 31.12.19, P1-R). At diagnosis, P1 displayed silencing of the Ara-C influx transporters ENT1, CNT3 and OCTN1 (Fig. 2a), as well downregulation of $\mathrm{dCK}$, the rate-limiting enzyme in Ara-C pro-drug activation (Fig. 2c), compared to GR patients. This indicated a major impairment of both Ara-C uptake and bioactivation in P1, which would severely hinder its cytotoxic activity. Consistently, survival analysis using the GEPIA2 server revealed significant correlations between low expression levels of either CNT3 or OCTN1 and poor prognosis in AML (i.e. short OS, Fig. 3a, b); however, no such correlation was observed for low levels of ENT1 or dCK (Fig. 3c, d). Since dCK is absolutely required for Ara-C activation, a possible reason that $\mathrm{dCK}$ levels were not correlated to any specific disease outcome could be due to high expression of an inactive enzyme, i.e. through alternative splicing $[21,101,102]$, which might interfere with this analysis. The correlation between low OCTN1 expression and poor survival in AML is further supported by a previous study on pediatric AML patients, which established OCTN1 as an Ara-C influx transporter and showcased low OCTN1 expression as a predictor of poor survival in AML patients [32]. In the same study, ENT1 also displayed a similar, albeit less significant correlation; this trend was previously reported [12]. Regarding CNT3 silencing, we note that the CNT3 gene locus maps to chr9q21, which resides within the deleted region found in $15 \%$ of the blasts in P1; this is a well-established and frequently deleted region in AML patients [103105]. Considering these findings, Ara-C presumably had a minimal cytotoxic effect in the blasts of $\mathrm{P} 1$, rendering 

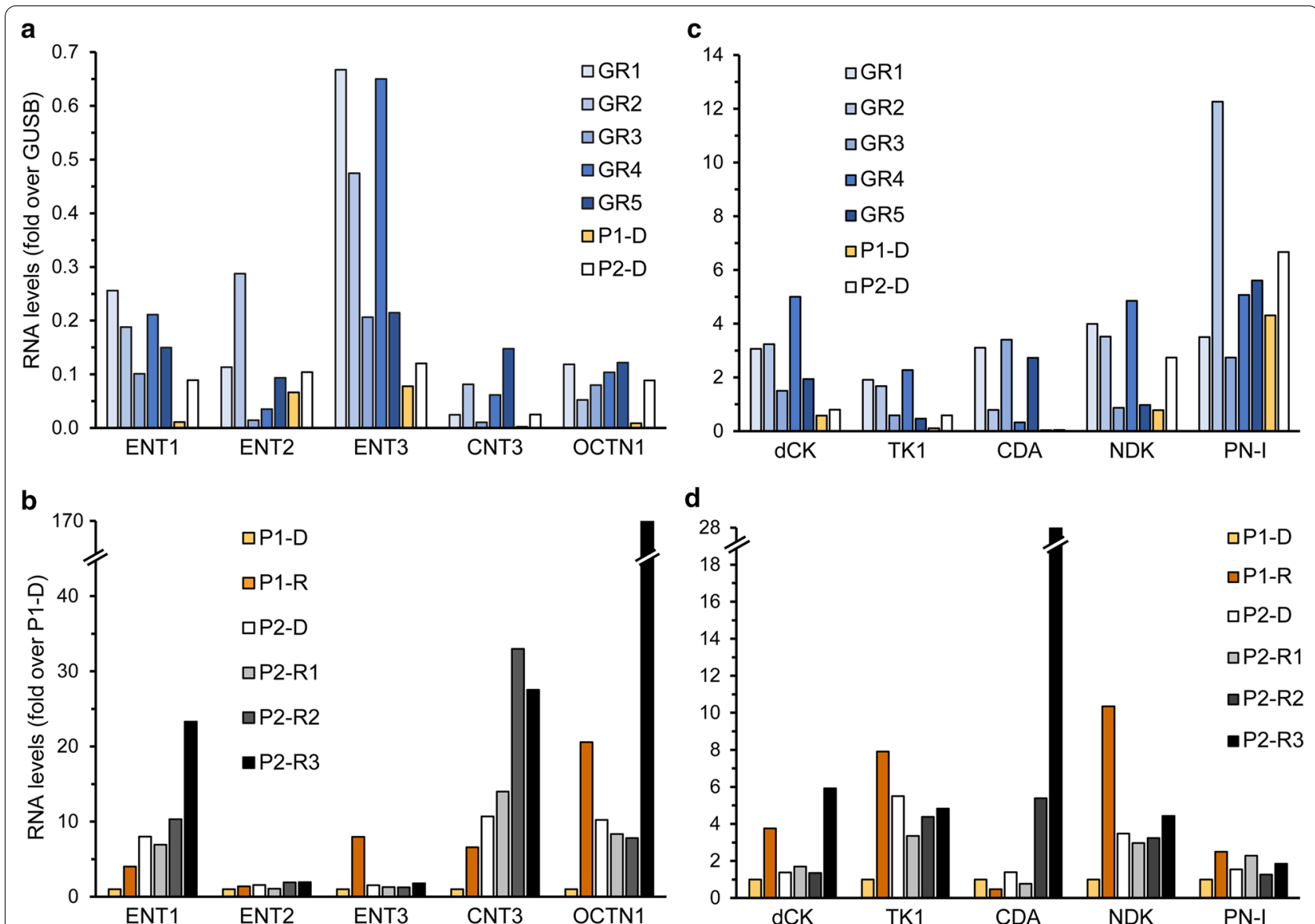

d

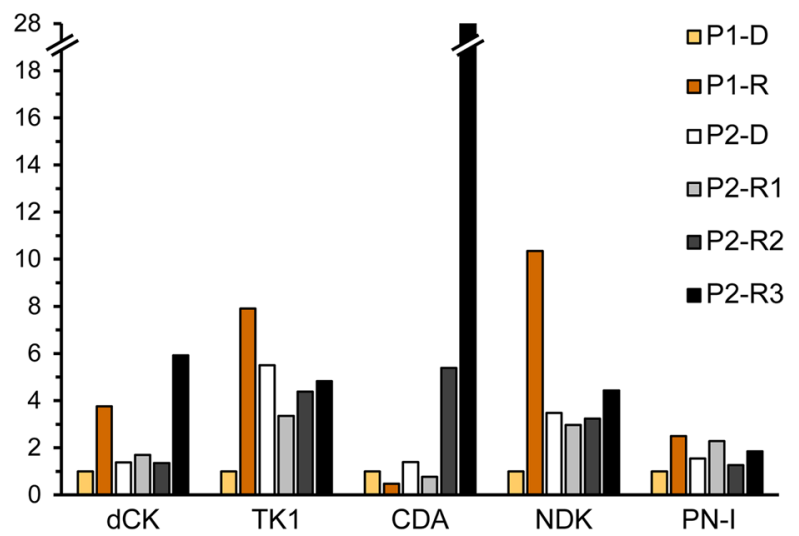

Fig. 2 Expression levels of nucleoside influx transporters and nucleoside salvage pathway enzymes. RNA was purified from AML patient specimens using tri reagent as described in the Methods section. Gene expression levels were determined using quantitative RT-PCR. $\mathbf{a}$, $\mathbf{b}$ Comparison of the expression levels at diagnosis in patients with good response to chemotherapy (GR1-5) and in relapsed patients (P1-D and P2-D). The results are presented as fold over GUSB which served as an internal control. c, d Comparison of the expression levels at the diagnosis and relapse stages in the relapsed patients. Results shown are normalized to GUSB which served as an internal control, and presented as fold over the expression levels of P1-D

its use in the induction and consolidation phases rather futile. We hence propose that patients could benefit from evaluating the gene expression status of Ara-C influx transporters prior to treatment, in order to ensure tumor cell accumulation of Ara-C especially in the presence of genomic deletions of the CNT3 locus. Although Ara-C might not have been effective, the induction treatment did induce remission in P1 presumably due to DNR cytotoxicity, since neither of the MDR efflux transporters, P-gp and BCRP, were substantially expressed at diagnosis (Fig. 4a, b).

Consistent with the downfalls of monotherapy [106], i.e. DNR as a single agent, P1 relapsed within nine months of DNR treatment. We therefore explored possible changes in gene expression that could have rendered the relapsed disease resistant to further drug treatment. The notably elevated P-gp levels at relapse (nearly 12 -fold over diagnosis, Fig. 4b) suggested clonal expansion of a
P-gp-dependent DNR-resistant clone, which presumably led to VP-16 and MX resistance [16, 47, 107]. Along this vein, since DNR is a lysosomotropic drug (LD) it might have induced an expansion of the lysosomal compartment $[55,56]$, rendering the cells resistant to other hydrophobic weak base drugs such as MX and VP-16 [29, $55,108-110]$. To explore the possible contribution of lysosomes to the chemoresistance that emerged at relapse, we tested the levels of two genes from the coordinated lysosomal expression and regulation (CLEAR) network $[111,112]$, which is upregulated upon drug-induced lysosomal biogenesis $[55,98]$. We found a major upregulation of both the lysosomal acidification pump V-type proton ATPase subunit H (ATP6v1H, 11-fold, Fig. 4d) and the acidic lysosomal protease cathepsin D (CTSD, 25-fold, Fig. 4d) [111], which indicated a stable expansion of the lysosomal compartment. To corroborate lysosomal drug 

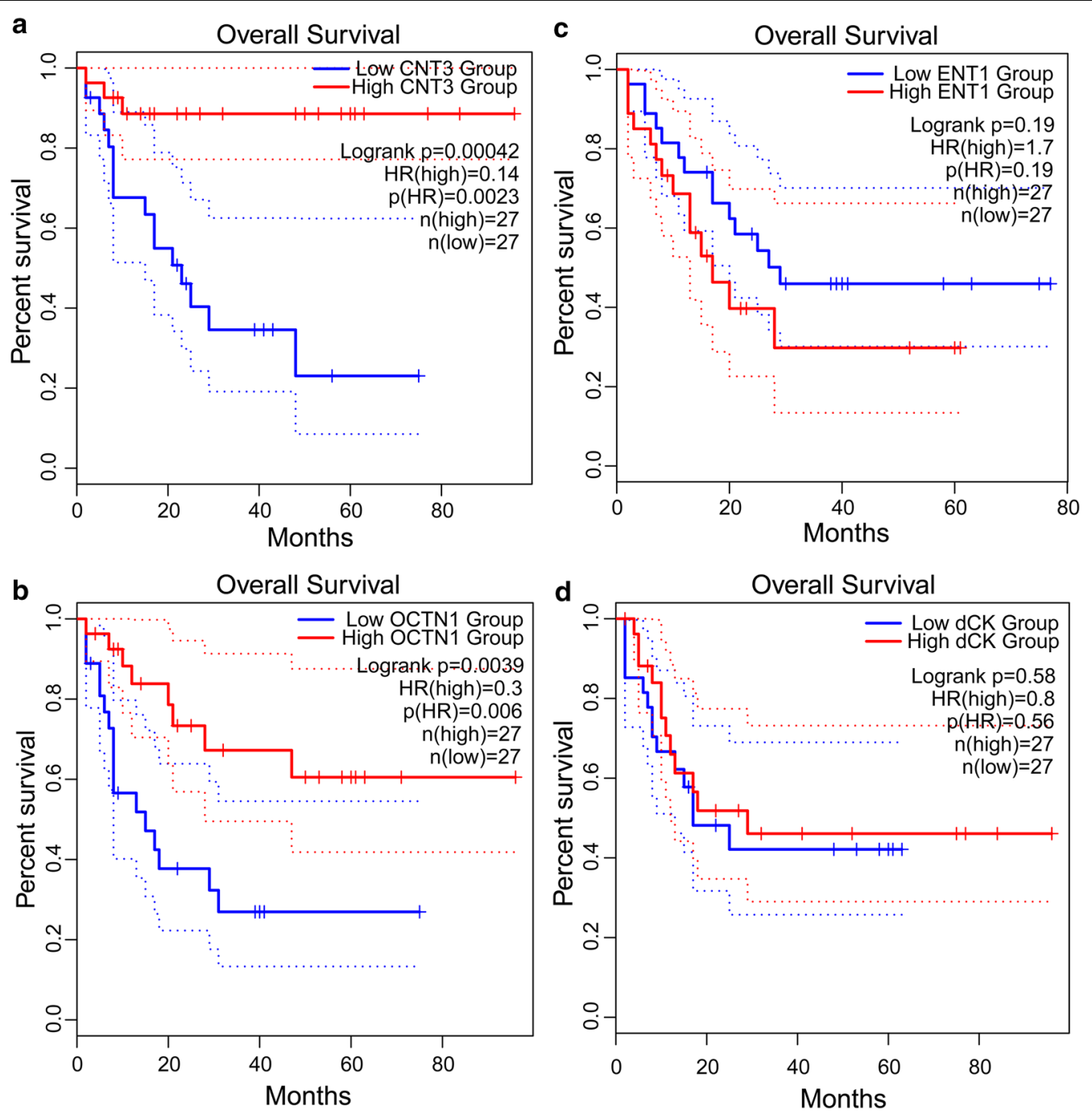

Fig. 3 Correlation of gene expression levels with overall survival in AML. The GEPIA2 server was used to generate correlation analyses between gene expression levels in AML bone marrow specimens from the cancer genome atlas (TCGA) and overall patient survival. Gene expression levels were normalized to POLR1D

sequestration at relapse, we chose representative genes that are dramatically elevated upon lysosomal dysfunction following treatment with LDs. Various LDs have been shown to hinder the export of cholesterol from lysosomes, where cholesterol accumulates [113-116], leading to enhanced expression of mevalonate pathway genes in an attempt to compensate for the low cellular cholesterol levels $[114,115]$. Indeed, the gene expression levels of the cholesterol biosynthesis enzymes methylsterol monooxygenase 1 (MSMO1) and 3-hydroxy-3-methylglutaryl-coenzyme A reductase (HMGCR) were dramatically increased post relapse (i.e. 34- and 16-fold over diagnosis, respectively, Fig. 4e).
Increased expression levels of the anti-apoptotic genes BCL2, BCLX(L) and MCL1 post-relapse ( 4-, 7-, and 8 -fold over diagnosis, respectively, Fig. 5) indicated an aggressive anti-apoptotic AML phenotype underlying resistance to VEN, as was previously reported $[67,68$, 70].

Alongside the inhibition of apoptosis, P1-R displayed enhanced expression of nucleoside salvage and biosynthesis genes that could support enhanced DNA replication. The activated nucleoside salvage pathway included the nucleoside influx transporters ENT3 and OCTN1 (8- and 20-fold increase, respectively, Fig. 2b), and the nucleoside kinases dCK, TK1 and NDK (4-, 8-, and 


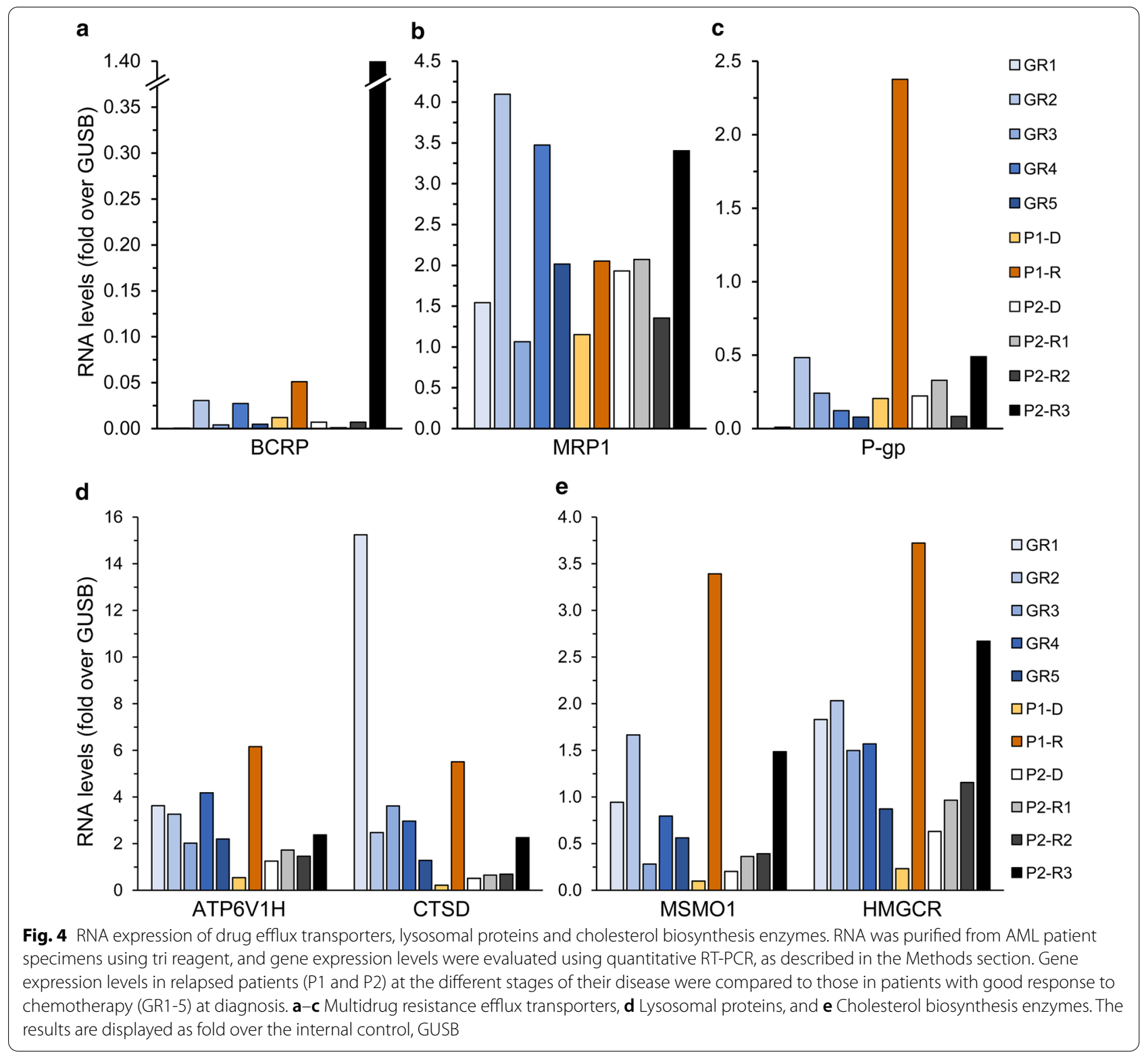

10-fold, respectively, Fig. 2d). Additionally, there was a 2.5 -fold increase in the gene expression levels of cytosolic 5'-nucleotidase 3A (cN-III/PN-I, Fig. 2d), that could dephosphorylate Ara-CMP and counteract its cytotoxic activity [117-120], which might have otherwise been increased upon upregulation of OCTN1, dCK and NDK.

In addition to the nucleoside salvage pathway, the de novo nucleotide synthesis pathway (DNSP) was also significantly activated following drug treatment, along with the relevant folate metabolism genes (Fig. 6 \& Additional file 1: Figs. S2-S4). This entailed upregulation of the mRNA levels of all genes studied including: the trifunctional CAD enzyme (CAD, 10-fold), CTP synthase 1 (CTPS1, 2-fold), uridine 5'-monophosphate synthase (UMPS, 7-fold), thymidylate synthase (TYMS, 18-fold), ribonucleoside-diphosphate reductase subunit M1 (RRM1, 9-fold), dihydrofolate reductase (DHFR, 8-fold), phosphoribosylglycinamide formyltransferase (GART, Trifunctional purine biosynthetic protein adenosine-3, 5-fold), reduced folate carrier (RFC,

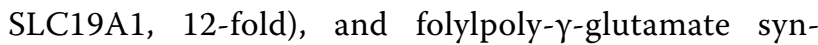
thetase (FPGS, 7-fold). Apart from enabling enhanced DNA replication, upregulation of DNSP genes can lead to an expansion of the cellular nucleotide pools including dCTP, which might further competitively negate 

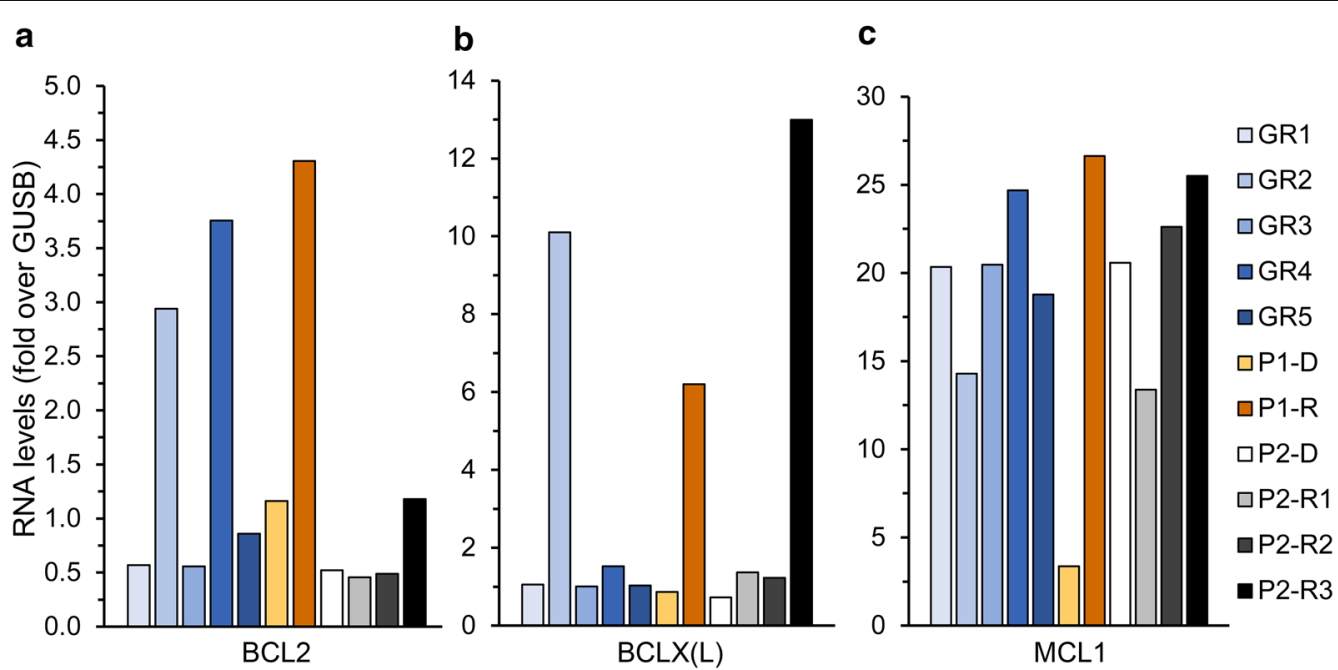

Fig. 5 RNA expression of genes encoding for anti-apoptotic proteins. RNA was purified from AML patient specimens using tri reagent, and gene expression levels were quantified using RT-PCR as described in the Methods section. The expression levels of Bcl-2 (a), Bcl-XL (b), and Mcl-1 (c) in relapsed patients (P1 and P2) at different stages of their disease, were compared to those in patients with good response to chemotherapy (GR1-5) at diagnosis. The results are presented as fold over the internal control, GUSB

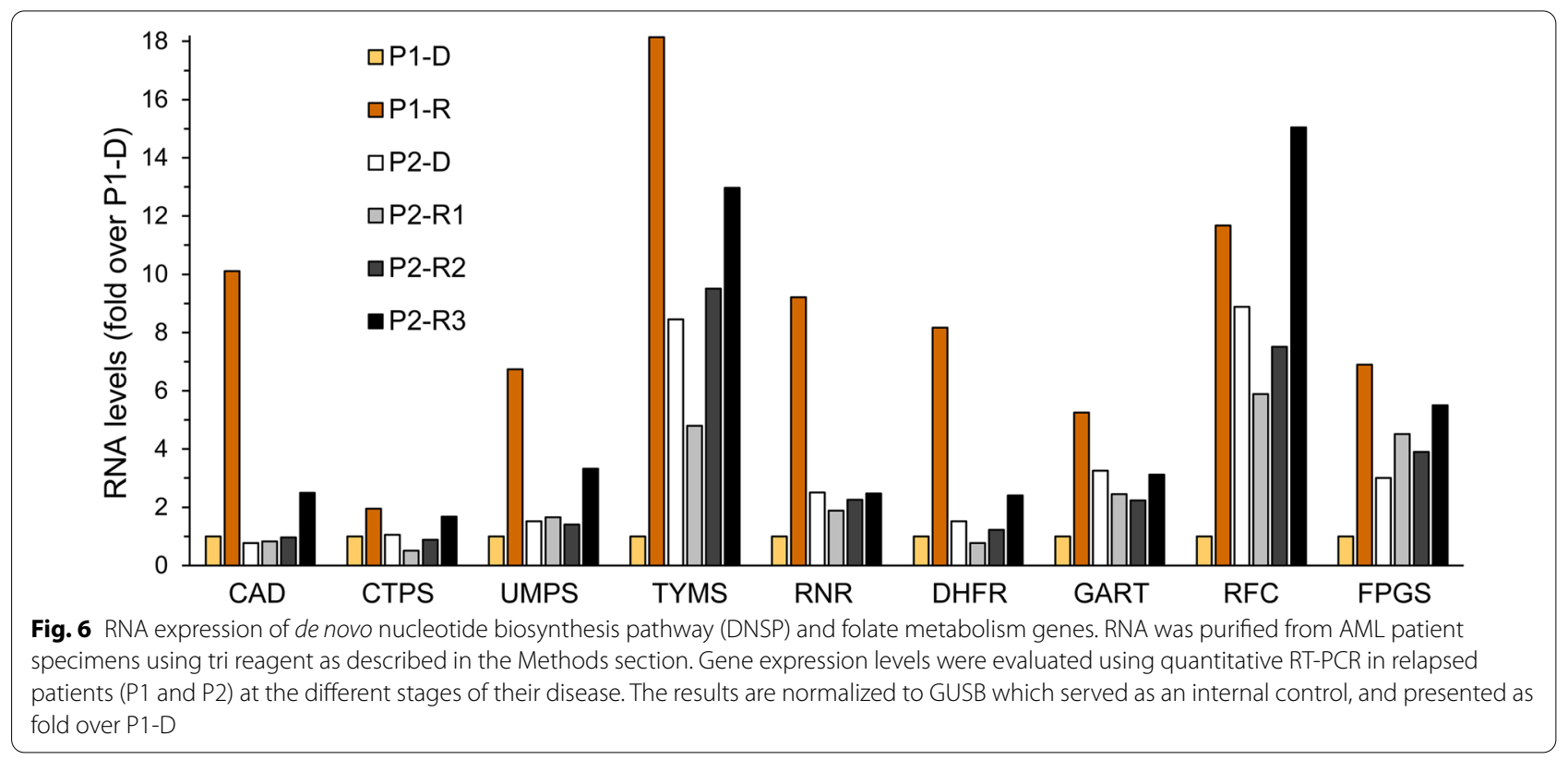

Ara-C cytotoxicity [121]. In this respect, upregulation of RRM1 can lead to increased cellular dCTP levels, thereby inhibiting dCK-mediated Ara-C activation and blocking Ara-CTP incorporation into DNA [43].

Performing an analysis, such as the one presented here, prior to the treatment decision might have revealed a superior personalized treatment modality, for example by targeting the DNSP using a combination of azidothymidine (AZT) and hydroxyurea (HU) as we have recently demonstrated [42]. This plausible treatment modality could be specifically viable in light of the upregulation of TK1 (Fig. 2d), which could lead to enhanced AZT activation [122-124]. While AZTMP is a substrate of the inactivating PN-I, its $K_{\mathrm{m}}$ value is 120 -fold higher 


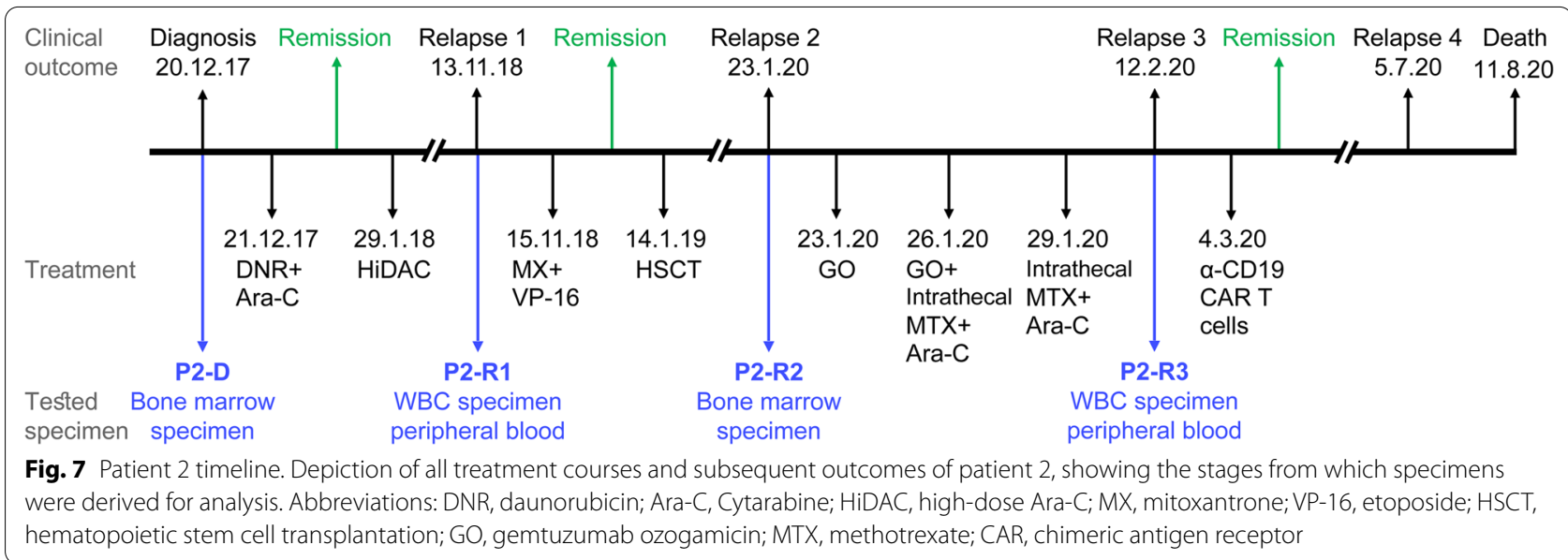

than that of CMP [118], and to date, there have been no reports of PN-I-mediated AZT resistance.

\section{Patient 2}

P2 was diagnosed with AML on December 20th, 2017 (Fig. 7, Table 2), and harbored the recurrent translocation $\mathrm{t}(8 ; 21)$, considered as the most favorable cytogenetic abnormality [125]. She underwent remission following standard Ara-C and DNR induction therapy, and remained disease-free for eleven months after consolidation treatment with HiDAC. Gene expression analysis on the diagnosis sample of P2 (20.12.17, P2-D) revealed levels of ENT1, CNT3 and OCTN1 comparable to those of the GR patients (Fig. 2a), indicating sufficient Ara-C influx; and while dCK levels were relatively low (Fig. 2c), NDK levels were high and the Ara-C catabolic enzyme CDA was not expressed (Fig. 2c), suggesting sufficient Ara-C activation. Moreover, the low expression levels of BCRP and P-gp along with comparable levels of MRP1 (Fig. 4a-c) supported the cellular accumulation of DNR. However, despite these apparently positive characteristics, relapse occurred.

At the first relapse (13.11.18, P2-R1), within the scope of genes we studied, there was no evidence of pertinent gene expression alterations that might directly underlie or lead to chemotherapy resistance. There was a moderate increase in the RNA levels of the anti-apoptotic protein Bcl-XL (1.9-fold relative to diagnosis level, Fig. 5b), albeit not higher than in the reference GR patients. Interestingly, MSMO1 and HMGCR expression levels started to rise (1.8- and 1.5-fold relative to diagnosis levels, Fig. 4e), possibly due to the lysosomotropic activity of DNR, as discussed above. However, there was no marked LD-associated resistance, as the salvage treatment composed of MX and VP-16 led to a second remission. This was followed by an allogeneic HSCT and durable remission for another 12 months.

At the second relapse (23.1.20, P2-R2), there was a 3 -fold increase in CNT3 expression levels (Fig. 2b), which could imply an attempt to enhance nucleoside salvage to support DNA replication. Moreover, there was a 4-fold increase in the transcript levels of CDA. Since this CDA increase was not observed in P2-R1, we cannot determine that it was induced by the HiDAC consolidation treatment, 13 months earlier. These changes were detrimental to the next salvage treatment of GO $\left(3 \mathrm{~g} / \mathrm{m}^{2}, 3\right.$ doses) followed by intrathecal methotrexate (MTX, 12.5 $\mathrm{mg}$ ) and Ara-C (30 mg), which failed to induce remission.

Three weeks after R2, when disease persistence was assessed (12.2.20, P2-R3), the patient displayed a further increase in CDA mRNA levels ( 5-fold over R2, and 20 -fold over diagnosis, Fig. 2d), possibly due to a rapid clonal expansion of cells detected in P2-R2. At R3, P2 exhibited multiple modes of MDR: (1) Increased CDA expression which presumably constituted the underlying basis for the recent Ara-C resistance [24]. (2) A marked 20-fold increase in BCRP mRNA levels, and a 2-fold increase in MRP1 levels (Fig. 4a, b) led to MTX-resistance, as MTX is a bona fide transport substrate of BCRP $[15,16]$ and MRP1 $[15,126]$. (3) The apparent increase in MRP1 levels together with that of P-gp (Fig. 4c) might have decreased cellular GO levels, hence reducing its cytotoxicity [73, 77, 127]. (4) The anti-apoptotic profile of P2 was exacerbated, including extreme upregulation of $\mathrm{BCLX}(\mathrm{L})$ (10-fold over R2, and 18-fold over diagnosis, Fig. 5b) and >2-fold increase in BCL2 levels (Fig. 5a); this contributed to both MTX [128, 129] and Ara-C [129] 
resistance. (5) The transcript levels of CTSD, MSMO1, and HMGCR were increased by 4.4-, 7.3- and 4.2-fold over diagnosis, respectively (Fig. $4 \mathrm{~d}$, e), indicating the expansion of the lysosomal compartment and drug sequestration; this could be relevant for the GO treatment which is metabolized in lysosomes [73]. Although further research is warranted to determine whether the GO conjugate or any of its derivatives might become sequestered within lysosomes, none of the other drugs after R2 could have triggered such a lysosomotropic response.

The continued upregulation of CNT3, and further increases in the gene expression levels of OCTN1, ENT1 (Fig. 2b) and dCK (Fig. 2d), indicated the upregulation of the nucleoside salvage pathway. The latter could have been strategically targeted with CDA-independent nucleoside analogs such as 6-mercaptopurine and 6-thioguanine [130-132], which would benefit from the increase in CNT3 levels [133].

Following the failure of the last treatment, and since P2 had CD19 positive blasts, she was able to receive CD19targeted chimeric antigen receptor (CAR) T cell therapy $[134,135]$, which resulted in a short remission of three months. Recent reports on the challenges of CAR T cell therapy in general [136], and specifically in AML due to its immunosuppressive microenvironment [137, 138], might explain the short duration of remission following the last treatment. At the last relapse, P2 suffered from sepsis during the HSCT procedure and succumbed to her disease, 32 months after the first diagnosis.

A summary of the chemotherapy-related gene expression alterations in the two patients is depicted in Fig. 8.

The current paper focused on two complex cases of relapsed AML in young patients. Both patients were characterized by aberrant expression of genes involved in the transport and metabolism of anchor chemotherapeutic drugs for AML treatment including Ara-C, DNR, MX, VP-16 and VEN. Therefore, both patients could have possibly benefited from a continuous assessment of expression of genes mediating drug activity or resistance with the aim to tailor efficacious personalized treatment regimens. While AML is a highly heterogeneous hematological malignancy with high prevalence of treatment failure, a handful of genes are invariably relevant for treatment outcome due to their direct role in drug transport and metabolism including drug influx and efflux, prodrug bioactivation, drug targets, drug inactivation or degradation as well as drug compartmentalization away from the drug target. Therefore, the expression status of these genes is crucial for predicting the potential

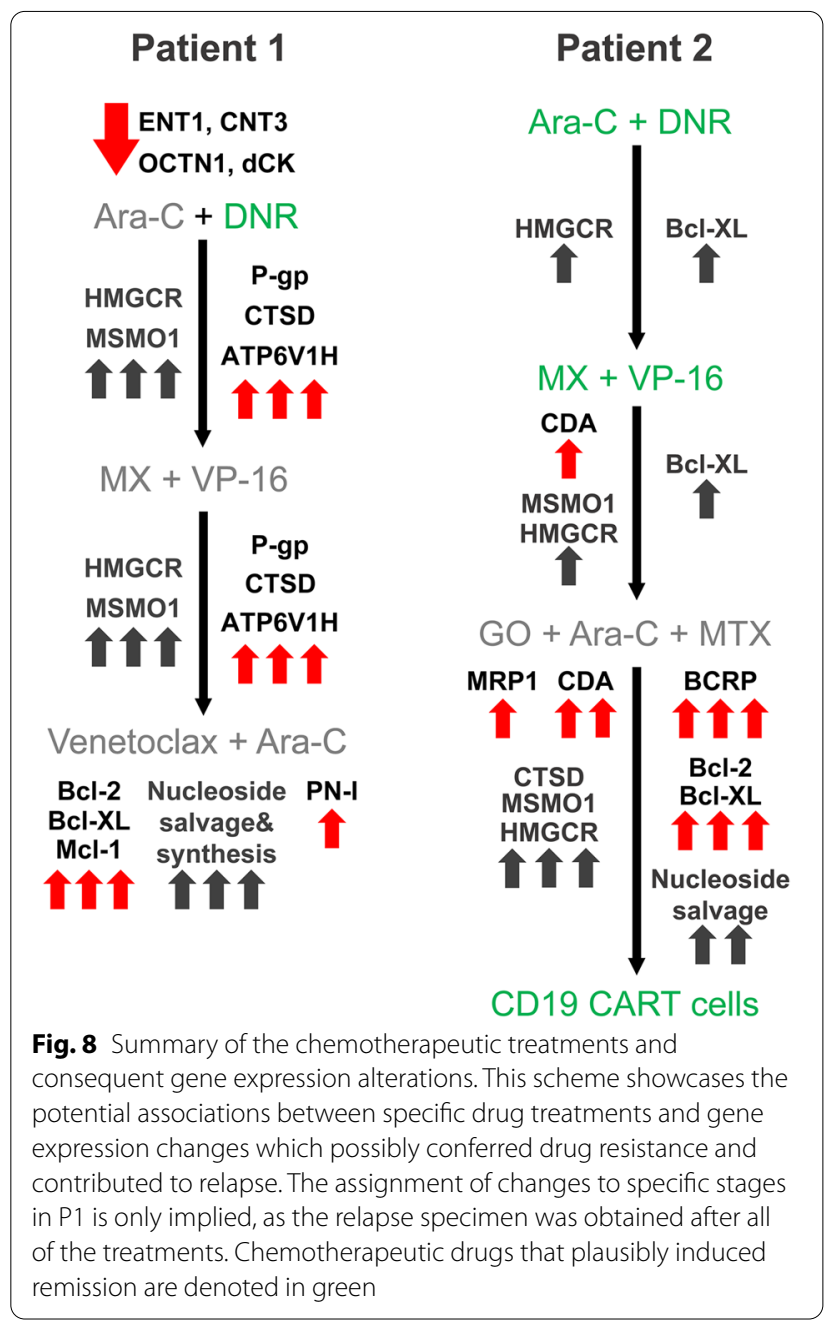

efficacy of specific treatments as well as assessing posttreatment response. This can allow for an optimal tailoring of chemotherapeutic regimens, thereby enhancing the achievement of long-term remissions. In this respect, special consideration should be given when selecting the drugs for the salvage treatment in relapsed disease. Since relapse usually occurs due to the expansion of resistant clones, if the salvage treatment is composed of drugs with the same characteristics (e.g. same cellular target, or influx/efflux transporters) as the induction drugs, it is likely that the same resistance mechanisms will hamper the cytotoxicity of the salvage drugs. For example, leukemic cells with intrinsic or acquired resistance to DNR 
either via downregulation of topoisomerase II [48, 139], upregulation of P-gp or expanded lysosomes, are likely to be cross-resistant to MX and VP-16, thereby inducing another relapse, since all of these drugs share similar cellular pathways. Similarly, leukemic cells that survived Ara-C cytotoxicity might be cross-resistant to other nucleoside analog prodrugs that share the same cellular uptake and activation routes. Consideration of drug action mechanisms and metabolism could further suggest potential combinations that may readily overcome chemoresistance modalities [42, 140-143].

The recent pervasiveness of next-generation, highthroughput techniques for sequencing, gene expression, and proteomics led to the identification of previously unpredicted genes that correlate with specific AML prognoses. However, big-data studies search for a common denominator in multiple patients and might lack molecular mechanistic insight into the role of specific gene expression alterations in disease progression and therapy response. The results of the current study, in concordance with a previous paper [144], suggest that AML patients would benefit from standardized testing of wellcharacterized relevant genes in order to tailor treatment regimens using a plethora of clinically available drugs. Given that conventional chemotherapy remains the cornerstone of AML treatment, and since chemoresistance continues to be the primary impediment towards curative AML treatment, real-time evaluation of drug resistance mechanisms remains a crucial task for the design of efficacious personalized AML treatments. For this to become a tangible possibility, there is a burning need to develop a standard protocol and/or a chip-based gene expression array that could be easily introduced into the clinical setting. Although, not all AML patients will benefit from such an analysis since some of the underlying resistance mechanisms may remain elusive, the prospect of improving patient survival rates along with minimization of adverse side effects inflicted by ineffective drug treatments, should be a priority of paramount importance.

\section{Conclusions}

The formidable heterogeneity of AML calls for the development of individualized treatment strategies. The genes studied in the current paper are crucial for treatment outcome and therefore should be routinely evaluated and taken into consideration when selecting the treatment of choice for individual AML patients. These evaluations are relevant both at the time of diagnosis to assess any potential preexisting resistance modalities, as well as at relapse in order to decipher the mechanisms underlying chemoresistance. Specifically, the risk of cross-resistance should be avoided by the administration of antitumor agents with distinct modes of action at consequent disease stages. Standard gene expression testing can help physicians to refrain from employing chemotherapy that would be ineffective in a specific patient, reduce unnecessary adverse effects, and in some cases even reveal a targeted personalized treatment possibility. In summary, towards a curative treatment of individual AML patients, we herein propose that an assortment of well-defined genes contributing to chemotherapeutic drug activity and/or chemoresistance be evaluated both at diagnosis as well as throughout the entire course of the disease in order to select the treatment of choice for individual AML patients.

\section{Supplementary Information}

The online version contains supplementary material available at https://doi. org/10.1186/s12935-021-01746-w.

Additional file 1: Figure. S1. Summary of drug metabolism. A graphical depiction of cellular transport, metabolism, and targets of AML chemotherapeutic drugs discussed in the manuscript. Pro-drug intermediates are colored in black, bioactive drugs are colored in light blue, and inactivated metabolites are colored in grey. Abbreviations: AICARFT, aminoimidazole4-carboxamide ribonucleotide formyltransferase; Ara-C, cytosine arabinoside; ATP6V1H, V-type proton ATPase subunit H; Bcl-2, B-cell leukemia/ lymphoma 2; $\mathrm{BCl}-\mathrm{XL}$, apoptosis regulator $\mathrm{BCl}-\mathrm{X}$, long isoform; $\mathrm{BCRP}$, breast cancer resistance protein; CDA, cytidine deaminase; CNT3, concentrative nucleoside transporter 3; CTSD, cathepsin D; dCK, deoxycytidine kinase; dCMPD, deoxycytidylate deaminase; dCMPK, deoxycytidylate kinase; DHFR, dihydrofolate reductase; DNR, daunorubicin;ENT1, esquilibrative nucleoside transporter 1; FPGS, folylpoly-y-glutamate synthetase; GO, Gemtuzumab Ozogamicin; HMGCR, 3-hydroxy-3-methylglutaryl-coenzyme A reductase; $\mathrm{Mcl}-1$, Induced myeloid leukemia cell differentiation protein $\mathrm{MCl}-1$; MRP, multidrug resistance-associated protein; MSMO1, methylsterol monooxygenase 1;MTX-polyG, methotrexate polyglutamate; MX, mitoxantrone; NDK, nucleoside diphosphate kinase; OCTN1, organic cation transporter, novel, type 1; PCFT, proton coupled folate transporter; P-gp, P-glycoprotein; PN-I, cytosolic 5-nuleotidase 3A; RFC, reduced folate carrier; TS, thymidylate synthase; VEN, venetoclax; VP-16, etoposide. Figure S2. Biosynthetic pathway of purine nucleotides. A graphical depiction of cellular de novo biosynthesis of purines. The enzymes that are discussed in the manuscript are colored in red. Abbreviations: ADSL, adenylosuccinate lyase;ADSS, adenylosuccinate synthase; AK, adenylate kinase; ATIC, 5-aminoimidazole-4-carboxamide ribonucleotide formyltransferase; GART, phosphoribosylglycinamide formyltransferase;GMPS, guanine monphosphate synthase;GUK1, guanylate kinase 1;IMPDH, inosine 5'-monophosphate dehydrogenase;NDK, nucleoside diphosphate kinase;PAICS, phosphoribosylaminoimidazole carboxylase;PFAS, phosphoribosylformylglycinamidine synthase; PPAT, phosphoribosyl pyrophosphate amidotransferase; PRPS1, phosphoribosyl pyrophosphate synthetase 1. Figure s3. Biosynthetic pathway of pyrimidine nucleotides. A graphical depiction of cellular de novo biosynthesis of pyrimidines. Blue arrows represent pyrimidine monophosphate synthesis through the salvage pathway. The enzymes that are discussed in the manuscript are colored in red. Abbreviations: $C A D$, trifunctional CAD enzyme; CMPK, cytidine monophosphate (UMP-CMP) kinase 1;CTPS, CTP synthase; dCK, deoxycytidine kinase; DCTD, 
deoxycytidine monophosphate deaminase; $\mathrm{DHODH}$, dihydroorotate dehydrogenase; DUT, deoxyuridine triphosphatase; NDK, nucleoside diphosphate kinase;UCK2, uridine-cytidine kinase 2; UMPS, uridine 5'-monophosphate synthase; RNR, ribonucleoside-diphosphate reductase; TK1, thymidine kinase 1; TMPK, thymidylate kinase; TS, thymidylate synthase. Figure S4. Cellular folate metabolism. A graphical depiction of cellular pathways utilizing folate cofactos. The enzymes that are discussed in the manuscript are colored in red. Abbreviations: ALDH1L2, aldehyde dehydrogenase 1 family, member L2; ATIC, 5-aminoimidazole-4-carboxamide ribonucleotide formyltransferase; $\mathrm{DHF}$, dihydrofolate; THF, tetrahydrofolate; DHFR, dihydrofolate reductase; DHFRL1, dihydrofolate reductaselike 1; GART, phosphoribosylglycinamide formyltransferase;MTHFD, methylenetetrahydrofolate dehydrogenase; MDHFD1L, methylenetetrahydrofolate dehydrogenase 1-like;MTHFR, methylenetetrahydrofolate reductase; MTHFS, 5,10-methenyltetrahydrofolate synthetase; MTR, 5-methyltetrahydrofolate-homocysteine methyltransferase; SHMT, serine hydroxymethyltransferase; TS, thymidylate synthase.

\section{Abbreviations}

AML: Acute myeloid leukemia; Ara-C: Cytosine arabinoside (cytarabine); DNR: Daunorubicin; MX: Mitoxantrone; VP-16: Etoposide; ABC: ATP-binding cassette; ENT: Equilibrative nucleoside transporte; CNT: concentrative nucleoside transporter; OCTN1: Organic cation transporter, novel, type 1; dCK: Deoxycytidine kinase; dCMPK: Deoxycytidylate kinase; NDK: Nucleoside diphosphate kinase; CDA: Cytidine deaminase; dCMPD: Deoxycytidine monophosphate deaminase; P-gp: P-glycoprotein; MDR: Multidrug resistance; VEN: Venetoclax; GO: Gemtuzumab ozogamicin; MRP: Multidrug resistance-associated protein; HSCT: Hematopoietic stem cell transplantation; RT PCR: Real-time polymerase chain reaction; GUSB: Glucuronidase $\beta$; OS: Overall survival; POLR1D: DNAdirected RNA polymerase I subunit D; P1/2: Patient 1/2; HiDAC: High dose Ara-C; CR: Complete remission; WBC: White blood cells; GR: Good response; LD: Lysosomotropic drug; CLEAR: Coordinated lysosomal expression and regulation; ATP6V1H: V-type proton ATPase subunit H; CTSD: Cathepsin D; MSMO1: Methylsterol monooxygenase 1; HMGCR: 3-hydroxy-3-methylglutaryl-coenzyme A reductase; DNSP: de novo synthesis pathway; CAD: Trifunctional CAD enzyme; CTPS1: CTP synthase 1; UMPS: Uridine 5'-monophosphate synthase; TYMS: Thymidylate synthase; AICARFT: Aminoimidazole-4-carboxamide ribonucleotide formyltransferase; RRM1: Ribonucleoside-diphosphate reductase subunit M1; DHFR: Dihydrofolate reductase; GART: Phosphoribosylglycinamide formyltransferase; RFC: Reduced folate carrier; FPGS: Folylpoly-y-glutamate synthetase; AZT: Azidothymidine; HU: Hydroxyurea; MTX: Methotrexate; CAR: Chimeric antigen receptor.

\section{Acknowledgements}

Not applicable.

\section{Authors' contributions}

ML, MS, and YGA conceptualized the study. YO collected and provided patient specimens. ML and MS performed the experiments. ML, MS and YGA analyzed the data. ML prepared the figures. MS and YGA supervised the study. ML, MS, and YGA wrote the manuscript. All authors read and approved the final manuscript.

\section{Funding}

Not applicable.

\section{Availability of data and materials}

All data generated or analyzed during this study are included in this published article.

\section{Ethics approval and consent to participate}

The use of human samples in this study was approved by the IRB committee (study number RMB 076-15) following informed consent by the patients in accordance with the Declaration of Helsinki.

\section{Consent for publication}

Not applicable.

\section{Competing interests}

The authors declare that they have no competing interests

Received: 8 October 2020 Accepted: 2 January 2021

Published online: 14 January 2021

\section{References}

1. Shipley JL, Butera JN. Acute myelogenous leukemia. Exp Hematol. 2009:37:649-58.

2. Blum WG, Mims AS. Treating acute myeloid leukemia in the modern era: a primer. Cancer. 2020;126:4668.

3. Patel SA, Gerber JM. A user's guide to novel therapies for acute myeloid leukemia. Clin Lymphoma Myeloma Leukemia. 2020;20:277-88.

4. Lai C, Doucette K, Norsworthy K. Recent drug approvals for acute myeloid leukemia. J Hematol Oncol. 2019;12:100.

5. Cancer Statistics Review, 1975-2017-SEER Statistics. https://seer.cance r.gov/csr/1975_2017/. Accessed 18 Jul 2020.

6. Heuser M, Ofran Y, Boissel N, Brunet Mauri S, Craddock C, Janssen J, et al. Acute myeloid leukaemia in adult patients: ESMO clinical practice guidelines for diagnosis, treatment and follow-upt. Ann Oncol. 2020;31:697-712.

7. Ravandi F, Pierce S, Garcia-Manero G, Kadia T, Jabbour E, Borthakur $\mathrm{G}$, et al. Salvage therapy outcomes in a historical cohort of patients with relapsed or refractory acute myeloid leukemia. Clin Lymphoma Myeloma Leuk. 2020. https://doi.org/10.1016/j.clml.2020.06.007.

8. Lazzarino M, Morra E, Alessandrino EP, Orlandi E, Pagnucco G, Merante $\mathrm{S}$, et al. Mitoxantrone and etoposide: an effective regimen for refractory or relapsed acute myelogenous leukemia. Eur J Haematol. 1989:43:411-6.

9. Assaraf YG, Brozovic A, Gonçalves AC, Jurkovicova D, Linē A, Machuqueiro $\mathrm{M}$, et al. The multi-factorial nature of clinical multidrug resistance in cancer. Drug Resist Updat. 2019;46:100645.

10. Li W, Zhang H, Assaraf YG, Zhao K, Xu X, Xie J, et al. Overcoming ABC transporter-mediated multidrug resistance: Molecular mechanisms and novel therapeutic drug strategies. Drug Resistance Updates. 2016;27:14-29.

11. Kanno S, Hiura T, Ohtake T, Koiwai K, Suzuki H, Ujibe M, et al. Characterization of resistance to cytosine arabinoside (Ara-C) in NALM-6 human B leukemia cells. Clin Chim Acta. 2007;377:144-9.

12. Galmarini CM, Thomas X, Calvo F, Rousselot P, Rabilloud M, El Jaffari A, et al. In vivo mechanisms of resistance to cytarabine in acute myeloid leukaemia. Br J Haematol. 2002;117:860-8.

13. Boswell-Casteel RC, Hays FA. Equilibrative nucleoside transporters-a review. Nucleosides, Nucleotides Nucleic Acids. 2017;36:7-30.

14. Zhang J, Visser F, King KM, Baldwin SA, Young JD, Cass CE. The role of nucleoside transporters in cancer chemotherapy with nucleoside drugs. Cancer Metastasis Rev. 2007;26:85-110.

15. Assaraf YG. The role of multidrug resistance efflux transporters in antifolate resistance and folate homeostasis. Drug Resist Updat. 2006;9:227-46.

16. Xia CQ, Smith PG. Drug efflux transporters and multidrug resistance in acute leukemia: therapeutic impact and novel approaches to mediation. Mol Pharmacol. 2012;82:1008-21.

17. Abraham A, Varatharajan S, Karathedath S, Philip C, Lakshmi KM, Jayavelu AK, et al. RNA expression of genes involved in cytarabine metabolism and transport predicts cytarabine response in acute myeloid leukemia. Pharmacogenomics. 2015;16:877-90.

18. Månsson E, Flordal E, Liliemark J, Spasokoukotskaja T, Elford H, Lagercrantz $\mathrm{S}$, et al. Down-regulation of deoxycytidine kinase in human leukemic cell lines resistant to cladribine and clofarabine and increased ribonucleotide reductase activity contributes to fludarabine resistance. Biochem Pharmacol. 2003;65:237-47.

19. Hodzic J, Giovannetti E, Calvo BD, Adema AD, Peters GJ, Peters GJ. Regulation of deoxycytidine kinase expression and sensitivity to gemcitabine by micro-RNA 330 and promoter methylation in cancer cells. Nucleosides, Nucleotides Nucleic Acids. 2011:30:1214-22.

20. Lotfi K, Juliusson G, Albertioni F. Pharmacological Basis for Cladribine Resistance. Leuk Lymphoma. 2003;44:1705-12. 
21. Veuger MJ, Honders MW, Landegent JE, Willemze R, Barge RM. High incidence of alternatively spliced forms of deoxycytidine kinase in patients with resistant acute myeloid leukemia. Blood. 2000;96:1517-24.

22. Stegmann AP, Honders MW, Kester MG, Landegent JE, Willemze R. Role of deoxycytidine kinase in an in vitro model for AraC- and DACresistance: substrate-enzyme interactions with deoxycytidine, 1-betaD-arabinofuranosylcytosine and 5-aza-2'-deoxycytidine. Leukemia. 1993;7:1005-11.

23. Månsson E, Spasokoukotskaja T, Sällström J, Eriksson S, Albertioni F. Molecular and biochemical mechanisms of fludarabine and cladribine resistance in a human promyelocytic cell line. Cancer Res. 1999:59:5956-63.

24. Fanciullino R, Farnault L, Donnette $M$, Imbs D-C, Roche C, Venton $\mathrm{G}$, et al. CDA as a predictive marker for life-threatening toxicities in patients with AML treated with cytarabine. Blood Adv. 2018;2:462-9.

25. Mao Y, Yu C, Hsieh TS, Nitiss JL, Liu AA, Wang H, et al. Mutations of human topoisomerase lla affecting multidrug resistance and sensitivity. Biochemistry. 1999;38:10793-800.

26. Okada Y, Tosaka A, Nimura Y, Kikuchi A, Yoshida S, Suzuki M. Atypical multidrug resistance may be associated with catalytically active mutants of human DNA topoisomerase II a. Gene. 2001;272:141-8.

27. Urasaki Y, Ueda T, Yoshida A, Fukushima T, Takeuchi N, Tsuruo T, et al. Establishment of a daunorubicin-resistant cell line which shows multi-drug resistance by multifactorial mechanisms. Anticancer Res. 1996;16:709-14

28. Assaraf YG. Molecular basis of antifolate resistance. Cancer Metastasis Rev. 2007;26:153-81.

29. Zhitomirsky B, Assaraf YG. Lysosomes as mediators of drug resistance in cancer. Drug Resist Updat. 2016;24:23-33.

30. Grant S. Ara-C: cellular and molecular pharmacology. Adv Cancer Res. 1998;72:197-233.

31. Yee SW, Mefford JA, Singh N, Percival M-E, Stecula A, Yang K, et al. Impact of polymorphisms in drug pathway genes on diseasefree survival in adults with acute myeloid leukemia. J Hum Genet. 2013;58:353-61.

32. Drenberg CD, Gibson AA, Pounds SB, Shi L, Rhinehart DP, Li L, et al. OCTN1 is a high-affinity carrier of nucleoside analogues. Cancer Res. 2017:77:2102-11.

33. Damaraju VL, Damaraju S, Young JD, Baldwin SA, Mackey J, Sawyer MB et al. Nucleoside anticancer drugs: the role of nucleoside transporters in resistance to cancer chemotherapy. Oncogene. 2003;22:7524-36.

34. Cai J, Damaraju VL, Groulx N, Mowles D, Peng Y, Robins MJ, et al. Two distinct molecular mechanisms underlying cytarabine resistance in human leukemic cells. Cancer Res. 2008;68:2349-57.

35. Bhise NS, Lamba V, Lamba J. Microrna expression and drug-induced changes in gene expression correlate with Ara-C chemosensitivity in AML cell lines. Blood. 2014;124.

36. Song JH, Cho K-M, Kim H-J, Kim Y-K, Kim NY, Kim H-J, et al. Concentrative nucleoside transporter 3 as a prognostic indicator for favorable outcome of $\mathrm{t}(8 ; 21)$-positive acute myeloid leukemia patients after cytarabine-based chemotherapy. Oncol Rep. 2015:34:488-94.

37. Nowak D, Liem NLMM, Mossner M, Klaumunzer M, Papa RA, Nowak $V$, et al. Variegated clonality and rapid emergence of new molecular lesions in xenografts of acute lymphoblastic leukemia are associated with drug resistance. Exp Hemat. 2015;43:32-43.e435.

38. Rathe SK, Largaespada DA. Deoxycytidine kinase is downregulated in Ara-C-resistant acute myeloid leukemia murine cell lines. Leukemia. 2010;24:1513-5.

39. Song JH, Kim SH, Kweon SH, Lee TH, Kim H-J, Kim H-J, et al. Defective expression of deoxycytidine kinase in cytarabine-resistant acute myeloid leukemia cells. Int J Oncol. 2009;34:1165-71.

40. Veuger MJT, Heemskerk MHM, Honders MW, Willemze R, Barge RMY. Functional role of alternatively spliced deoxycytidine kinase in sensitivity to cytarabine of acute myeloid leukemic cells. Blood. 2002;99:1373-80.

41. Degwert N, Latuske E, Vohwinkel G, Stamm H, Klokow M, Bokemeyer C, et al. Deoxycytidine kinase is downregulated under hypoxic conditions and confers resistance against cytarabine in acute myeloid leukaemia. Eur J Haematol. 2016:97:239-44

42. Levin M, Stark M, Berman B, Assaraf YG. Surmounting Cytarabineresistance in acute myeloblastic leukemia cells and specimens with a synergistic combination of hydroxyurea and azidothymidine. Cell Death Dis. 2019;10:1

43. Lamba JK. Genetic factors influencing cytarabine therapy. Pharmacogenomics. 2009;10:1657-74.

44. Regev R, Yeheskely-Hayon D, Katzir H, Eytan GD. Transport of anthracyclines and mitoxantrone across membranes by a flip-flop mechanism. Biochem Pharmacol. 2005:70:161-9.

45. Fukushima T, Takemura H, Yamashita T, Ishisaka T, Inai K, Imamura S, et al. Multidrug resistance due to impaired DNA cleavage in a VP16-resistant human leukemia cell line. Anticancer Res. 1999;19:5111-5.

46. Jaffrézou JP, Chen G, Durán GE, Kühl JS, Sikic BI. Mutation rates and mechanisms of resistance to etoposide determined from flucattion analysis. J Natl Cancer Inst. 1994;86:1152-8.

47. Long BH, Wang L, Lorico A, Wang RCC, Brattain MG, Casazza AM. Mechanisms of resistance to etoposide and teniposide in acquired resistant human colon and lung carcinoma cell lines.' Cancer Res. 1991;51:5275-83.

48. Friche E, Danks MK, Schmidt CA, Beck WT. Decreased DNA topoisomerase II in daunorubicin-resistant ehrlich ascites tumor cells. Cancer Res. 1991;51:4213.

49. Ross DD, Wooten PJ, Sridhara R, Ordonez JV, Lee EJ, Schiffer CA. Enhancement of daunorubicin accumulation, retention, and cytotoxicity by verapamil or cyclosporin A in blast cells from patients with previously untreated acute myeloid leukemia. Blood. 1993;82:1288-99.

50. Nielsen D, Maare C, Skovsgaard T. Cellular resistance to anthracyclines. Gen Pharmacol. 1996;27:251-5.

51. Choi $\mathrm{CH}$, Ling V. Isolation and characterization of daunorubicin-resistant AML-2 sublines. Mol Cells. 1997;7:170-7.

52. Gewirtz DA. A critical evaluation of the mechanisms of action proposed for the antitumor effects of the anthracycline antibiotics adriamycin and daunorubicin. Biochem Pharmacol. 1999:57:727-41.

53. Vasanthakumar G, Ahmed NK. Uptake and metabolism of daunorubicin by human myelocytic cells. Cancer Chemother Pharmacol. 1985;15:35-9

54. Bogason A, Masquelier M, Lafolie P, Skogastierna C, Paul C, Gruber A, et al. Daunorubicin metabolism in leukemic cells isolated from patients with acute myeloid leukemia. Drug Metab Lett. 2010;4:228-32.

55. Zhitomirsky B, Assaraf YG. Lysosomal sequestration of hydrophobic weak base chemotherapeutics triggers lysosomal biogenesis and lysosomedependent cancer multidrug resistance. Oncotarget. 2015;6:1143-56

56. Stark M, Silva TFD, Levin G, Machuqueiro M, Assaraf YG. The lysosomotropic activity of hydrophobic weak base drugs is mediated via their intercalation into the lysosomal membrane. Cells. 2020;9:1082.

57. Biasoli D, Kahn SA, Cornélio TA, Furtado M, Campanati L, Chneiweiss $\mathrm{H}$, et al. Retinoblastoma protein regulates the crosstalk between autophagy and apoptosis, and favors glioblastoma resistance to etoposide. Cell Death Dis. 2013;4:e767.

58. Zhitomirsky B, Assaraf YG. Lysosomal accumulation of anticancer drugs triggers lysosomal exocytosis. Oncotarget. 2017;8:45117-32.

59. Makin G, Hickman JA. Apoptosis and cancer chemotherapy. Cell Tissue Res. 2000;301:143-52.

60. Kaufmann SH, Earnshaw WC. Induction of apoptosis by cancer chemotherapy. Exp Cell Res. 2000;256:42-9.

61. Ferrer A, Marcé S, Bellosillo B, Villamor N, Bosch F, López-Guillermo A, et al. Activation of mitochondrial apoptotic pathway in mantle cell lymphoma: high sensitivity to mitoxantrone in cases with functional DNA-damage response genes. Oncogene. 2004;23:8941-9.

62. Bailly JD, Skladanowski A, Bettaieb A, Mansat V, Larsen AK, Laurent G. Natural resistance of acute myeloid leukemia cell lines to mitoxantrone is associated with lack of apoptosis. Leukemia. 1997;11:1523-32.

63. Shahar N, Larisch S. Inhibiting the inhibitors: targeting anti-apoptotic proteins in cancer and therapy resistance. Drug Resist Updates. 2020:52:100712.

64. DiNardo CD, Pratz K, Pullarkat V, Jonas BA, Arellano M, Becker PS, et al. Venetoclax combined with decitabine or azacitidine in treatment-naive, elderly patients with acute myeloid leukemia. Blood. 2019;133:7-17

65. Pollyea DA, Amaya M, Strati P, Konopleva MY. Venetoclax for AML: changing the treatment paradigm. Blood Adv. 2019;3:4326-35. 
66. Ganzel C, Ram R Gural A Wolach O, Gino-Moor S, Vainstein V et al. Venetoclax is safe and efficacious in relapsed/ refractory AML. Blood. 2019;134(Supplement_1):5091-5091.

67. Hormi M, Birsen R, Belhadj M, Huynh T, Cantero Aguilar L, Grignano E, et al. Pairing MCL-1 inhibition with venetoclax improves therapeutic efficiency of BH3-mimetics in AML. Eur J Haematol. 2020;13492.

68. Pei S, Pollyea DA, Gustafson A, Stevens BM, Minhajuddin M, Fu R, et al. Monocytic subclones confer resistance to venetoclax-based therapy in patients with acute myeloid leukemia. Cancer Discov. 2020;10:536-51.

69. Pollyea DA, Stevens BM, Jones CL, Winters A, Pei S, Minhajuddin M, et al. Venetoclax with azacitidine disrupts energy metabolism and targets leukemia stem cells in patients with acute myeloid leukemia. Nat Med. 2018:24:1859-66.

70. Zhang Q, Han L, Shi C, Pan R, MA MCJ, Ryan J, et al. Upregulation of MAPK/MCL-1 Maintaining Mitochondrial Oxidative Phosphorylation Confers Acquired Resistance to BCL-2 Inhibitor Venetoclax in AML. Blood. 2016;128:101-101.

71. Ahmed F, Allehyani OA, Alfayez M, Schulten $\mathrm{H}-\mathrm{J}$, Alkhattabi $\mathrm{H}$, Chaudhary AGA, et al. Novel genetic mechanism of venetoclax resistance in AML: BAX Deletion. Blood. 2019;134(Supplement_1):5057-5057.

72. Weiss J, Gajek T, Köhler BC, Haefeli WE. Venetoclax (Abt-199) might act as a perpetrator in pharmacokinetic drug-drug interactions. Pharmaceutics. 2016;8:5.

73. Ricart AD. Antibody-drug conjugates of calicheamicin derivative: gemtuzumab ozogamicin and inotuzumab ozogamicin. Clin Cancer Res. 2011;17:6417-27.

74. Linenberger ML. CD33-directed therapy with gemtuzumab ozogamicin in acute myeloid leukemia: progress in understanding cytotoxicity and potential mechanisms of drug resistance. Leukemia. 2005:19:176-82.

75. Walker S, Landovitz R, Ding WD, Ellestad GA, Kahne D. Cleavage behavior of calicheamicin $\gamma 1$ and calicheamicin T. Proc Natl Acad Sci U S A. 1992;89:4608-12.

76. Taksin AL, Legrand O, Raffoux E, de Revel T, Thomas X, Contentin N, et al. High efficacy and safety profile of fractionated doses of Mylotarg as induction therapy in patients with relapsed acute myeloblastic leukemia: a prospective study of the alfa group. Leukemia. 2007;21:66-71.

77. Walter RB, Raden BW, Hong TC, Flowers DA, Bernstein ID, Linenberger ML. Multidrug resistance protein attenuates gemtuzumab ozogamicin-induced cytotoxicity in acute myeloid leukemia cells. Blood. 2003:102:1466-73.

78. Hopper-Borge E, Xu X, Shen T, Shi Z, Chen ZS, Kruh GD. Human multidrug resistance protein 7 (ABCC10) is a resistance factor for nucleoside analogues and epothilone B. Cancer Res. 2009;69:178-84.

79. Drenberg C, Hu S, Li L, Buelow D, Orwick S, Gibson A, et al. ABCC4 Is a determinant of cytarabine-induced cytotoxicity and myelosuppression. Clin Transl Sci. 2016:9:51-9.

80. Guo Y, Kock K, Ritter CA, Chen ZS, Grube M, Jedlitschky G, et al. Expression of ABCC-type nucleotide exporters in blasts of adult acute myeloid leukemia: relation to long-term survival. Clin Cancer Res. 2009;15:1762-9

81. Chauvier D, Morjani H, Manfait M. Homocamptothecin-daunorubicin association overcomes multidrug-resistance in breast cancer MCF7 cells. Breast Cancer Res Treat. 2002;73:113-25.

82. Stefan SM, Wiese M. Small-molecule inhibitors of multidrug resistanceassociated protein 1 and related processes: a historic approach and recent advances. Medicinal Res Rev. 2019;39:176-264.

83. Zunino F, Capranico G. DNA topoisomerase II as the primary target of anti-tumor anthracyclines. Anti-Cancer Drug Design. 1990;5:307-17.

84. Aubel-Sadron G, Londos-Gagliardi D. Daunorubicin and doxorubicin, anthracycline antibiotics, a physicochemical and biological review. Biochimie. 1984;66:333-52.

85. Evison BJ, Sleebs BE, Watson KG, Phillips DR, Cutts SM. Mitoxantrone, more than just another topoisomerase II poison. Med Res Rev. 2016:36:248-99.

86. Ma Y, Wink M. The beta-carboline alkaloid harmine inhibits BCRP and can reverse resistance to the anticancer drugs mitoxantrone and camptothecin in breast cancer cells. Phyther Res. 2010;24:146-9.

87. Nakanishi T, Doyle LA, Hassel B, Wei Y, Bauer KS, Wu S, et al. Functional Characterization of human breast cancer resistance protein (BCRP, ABCG2) expressed in the oocytes of Xenopus laevis. Mol Pharmacol. 2003:64:1452-62.
88. Morrow CS, Peklak-Scott C, Bishwokarma B, Kute TE, Smitherman PK, Townsend AJ. Multidrug resistance protein 1 (MRP1, ABCC1) mediates resistance to mitoxantrone via glutathione-dependent drug efflux. Mol Pharmacol. 2006;69:1499-505.

89. Wang X, Furukawa T, Nitanda T, Okamoto M, Sugimoto Y, Akiyama SI, et al. Breast cancer resistance protein (BCRP/ABCG2) induces cellular resistance to HIV-1 nucleoside reverse transcriptase inhibitors. Mol Pharmacol. 2003;63:65-72.

90. Ifergan I, Scheffer GL, Assaraf YG. Novel extracellular vesicles mediate an ABCG2-dependent anticancer drug sequestration and resistance. Cancer Res. 2005;65:10952-8.

91. Montecucco A, Zanetta F, Biamonti G. Molecular mechanisms of etoposide. EXCLI J. 2015;14:95-108.

92. Yang J, Bogni A, Schuetz EG, Ratain M, Eileen Dolan M, McLeod H, et al. Etoposide pathway. Pharmacogenetics Genomics. 2009;19:552-3.

93. Assaraf YG. Molecular basis of antifolate resistance. Cancer Metastasis Rev. 2007;26:153-81.

94. Gonen N, Assaraf YG. Antifolates in cancer therapy: Structure, activity and mechanisms of drug resistance. Drug Resist Updat. 2012;15:183-210.

95. Chiney MS, Menon RM, Bueno OF, Tong B, Salem AH. Clinical evaluation of P-glycoprotein inhibition by venetoclax: a drug interaction study with digoxin. Xenobiotica. 2018;48:904-10

96. Raz S, Sheban D, Gonen N, Stark M, Berman B, Assaraf YG. Severe hypoxia induces complete antifolate resistance in carcinoma cells due to cell cycle arrest. Cell Death Dis. 2014;5:e1067-e1067.

97. Evseenko DA, Murthi P, Paxton JW, Reid G, Emerald BS, Mohankumar $\mathrm{KM}$, et al. The $\mathrm{ABC}$ transporter BCRP/ABCG2 is a placental survival factor, and its expression is reduced in idiopathic human fetal growth restriction. FASEB J. 2007;21:3592-605.

98. Zhitomirsky B, Yunaev A, Kreiserman R, Kaplan A, Stark M, Assaraf YG Lysosomotropic drugs activate TFEB via lysosomal membrane fluidization and consequent inhibition of mTORC1 activity. Cell Death Dis. 2018;9:1191.

99. Gonen N, Assaraf YG. The obligatory intestinal folate transporter PCFT (SLC46A 1 ) is regulated by nuclear respiratory factor 1. J Biol Chem. 2010;285:33602-13.

100. Tang Z, Kang B, Li C, Chen T, Zhang Z. GEPIAZ: an enhanced web server for large-scale expression profiling and interactive analysis. Nucleic Acids Res. 2019;47:W556-60.

101. Veuger MJT, Honders MW, Willemze R, Barge RMY. Deoxycytidine kinase expression and activity in patients with resistant versus sensitive acute myeloid leukemia. Eur J Haematol. 2002;69:171-8.

102. Veuger MJT, Heemskerk MHM, Willy Honders M, Willemze R, Barge RMY. Functional role of alternatively spliced deoxycytidine kinase in sensitivity to cytarabine of acute myeloid leukemic cells. Blood. 2002;99:1373-80.

103. Peniket A, Wainscoat J, Side L, Daly S, Kusec R, Buck G, et al. Del (9q) AML: clinical and cytological characteristics and prognostic implications. Br J Haematol. 2005;129:210-20.

104. Naarmann-de Vries IS, Sackmann Y, Klein F, Ostareck-Lederer A, Ostareck $\mathrm{DH}$, Jost $\mathrm{E}$, et al. Characterization of acute myeloid leukemia with del(9q) -impact of the genes in the minimally deleted region. Leuk Res. 2019;76:15-23.

105. Balk B, Stengel A, Meggendorfer M, Fasan A, Kern W, Haferlach T, et al. Impact of $9 q$ Deletions on the classification in AML. Blood. 2017;130(Supplement 1):3925-3925.

106. Mokhtari RB, Homayouni TS, Baluch N, Morgatskaya E, Kumar S, Das $B$, et al. Combination therapy in combating cancer. Oncotarget. 2017:8:38022-43.

107. Consoli U, Van NT, Neamati N, Mahadevia R, Beran M, Zhao S, et al. Cellular pharmacology of mitoxantrone in p-glycoprotein-positive and -negative human myeloid leukemic cell lines. Leukemia. 1997:11:2066-74

108. Adar Y, Stark M, Bram EE, Nowak-Sliwinska P, Van Den Bergh H, Szewczyk $\mathrm{G}$, et al. Imidazoacridinone-dependent lysosomal photodestruction: a pharmacological Trojan horse approach to eradicate multidrug-resistant cancers. Cell Death Dis. 2012;3:e293.

109. Zhao B, Dierichs L, Gu JN, Trajkovic-Arsic M, Axel Hilger R, Savvatakis $\mathrm{K}$, et al. TFEB-mediated lysosomal biogenesis and lysosomal drug 
sequestration confer resistance to MEK inhibition in pancreatic cancer. Cell Death Discov. 2020;6:12

110. Li Y, Zou L, Li Q, Haibe-Kains B, Tian R, Le Y, et al. Amplification of LAPTM $4 B$ and YWHAZ contributes to chemotherapy resistance and recurrence of breast cancer. Nat Med. 2010;16:214-8.

111. Palmieri M, Impey S, Kang H, di Ronza A, Pelz C, Sardiello M, et al. Characterization of the CLEAR network reveals an integrated control of cellular clearance pathways. Hum Mol Genet. 2011;20:3852-66.

112. Settembre C, Fraldi A, Medina DL, Ballabio A. Signals from the lysosome: a control centre for cellular clearance and energy metabolism. Nat Rev Mol Cell Biol. 2013;14:283-96.

113. Kuzu OF, Gowda R, Sharma A, Robertson GP. Leelamine mediates cancer cell death through inhibition of intracellular cholesterol transport. Mol Cancer Ther. 2014;13:1690-703.

114. Filippakis H, Alesi N, Ogorek B, Nijmeh J, Khabibullin D, Gutierrez $\mathrm{C}$, et al. Lysosomal regulation of cholesterol homeostasis in tuberous sclerosis complex is mediated via NPC1 and LDL-R. Oncotarget. 2017:8:38099-112.

115. Kristiana I, Sharpe L, Catts VS, Lutze-Mann LH, Brown AJ. Antipsychotic drugs upregulate lipogenic gene expression by disrupting intracellular trafficking of lipoprotein-derived cholesterol. Pharmacogenomics J. 2010;10:396-407.

116. Kuzu OF, Toprak M, Noory MA, Robertson GP. Effect of lysosomotropic molecules on cellular homeostasis. Pharmacol Res. 2017:117:177-84.

117. Amici A, Emanuelli M, Magni G, Raffaelli N, Ruggieri S. Pyrimidine nucleotidases from human erythrocyte possess phosphotransferase activities specific for pyrimidine nucleotides. FEBS Lett. 1997:419:263-7.

118. Amici A, Magni G. Human erythrocyte pyrimidine $5^{\prime}$-nucleotidase. PN-I Arch Biochem Biophys. 2002;397:184-90

119. Li A, Fridley B, Kalari K, Jenkins G, Batzler A, Safgren S, et al. Gemcitabine and cytosine arabinoside cytotoxicity: Association with lymphoblastoid cell expression. Cancer Res. 2008;68:7050-8.

120. Hunsucker SA, Mitchell BS, Spychala J. The 5'-nucleotidases as regulators of nucleotide and drug metabolism. Pharmacol Therapeutics. 2005:107:1-30.

121. Iwasaki H, Huang P, Keating MJ, Plunkett W. Differential incorporation of ara-C, gemcitabine, and fludarabine into replicating and repairing DNA in proliferating human leukemia cells. Blood. 1997:90:270-8.

122. Lavie A, Schlichting I, Vetter IR, Konrad M, Reinstein J, Goody RS. The bottleneck in AZT activation. Nat Med. 1997:3:922-4.

123. Törnevik Y, Ullman B, Balzarini J, Wahren B, Eriksson S. Cytotoxicity of 3'-azido-3'-deoxythymidine correlates with 3'-azidothymidine5'-monophosphate (AZTMP) levels, whereas antihuman immunodeficiency virus (HIV) activity correlates with 3'-azidothymidine-5'triphosphate (AZTTP) levels in cultured CEM T-lymphoblastoid cells. Biochem Pharmacol. 1995:49:829-37.

124. Furman PA, Fyfe JA, St Clair MH, Weinhold K, Rideout JL, Freeman GA, et al. Phosphorylation of 3'-azido-3'-deoxythymidine and selective interaction of the $5^{\prime}$-triphosphate with human immunodeficiency virus reverse transcriptase. Proc Natl Acad Sci U S A. 1986;83:8333-7.

125. Estey EH. Acute myeloid leukemia: 2019 update on risk-stratification and management. Am J Hematol. 2018;93:1267-91.

126. Zeng H, Chen ZS, Belinsky MG, Rea PA, Kruh GD. Transport of methotrexate (MTX) and folates by multidrug resistance protein (MRP) 3 and MRP1: Effect of polyglutamylation on MTX transport. Cancer Res. 2001:61:7225-32.

127. Walter RB, Gooley TA, Van Der Velden VHJ, Loken MR, Van Dongen JJM, Flowers DA, et al. CD33 expression and P-glycoprotein-mediated drug efflux inversely correlate and predict clinical outcome in patients with acute myeloid leukemia treated with gemtuzumab ozogamicin monotherapy. Blood. 2007;109:4168-70.

128. Liu R, Page C, Beidler DR, Wicha MS, Núñez G. Overexpression of Bcl-X(L) promotes chemotherapy resistance of mammary tumors in a syngeneic mouse model. Am J Pathol. 1999:155:1861-7.

129. Miyashita T, Reed JC. BCl-2 Oncoprotein Blocks Chemotherapy-Induced Apoptosis in a Human Leukemia Cell Line.
130. Arthur C, Jeffrey A, Yip E, Katsioulas V, Nalpantidis A, Kerridge I, et al. Prolonged administration of low-dose cytarabine and thioguanine in elderly patients with acute myeloid leukaemia (AML) achieves high complete remission rates and prolonged survival. Leuk Lymphoma. 2020;61:831-9.

131. Choi YW, Jeong SH, Ahn MS, Lee HW, Kang SY, Choi JH, et al. Oral maintenance chemotherapy with 6-Mercaptopurine and methotrexate in patients with acute myeloid leukemia ineligible for transplantation. J Korean Med Sci. 2015;30:1416-22.

132. Ferrero D, Crisà E, Marmont F, Audisio E, Frairia C, Giai V, et al. Survival improvement of poor-prognosis AML/MDS patients by maintenance treatment with low-dose chemotherapy and differentiating agents. Ann Hematol. 2014;93:1391-400.

133. Fotoohi AK, Lindqvist M, Peterson C, Albertioni F. Involvement of the concentrative nucleoside transporter 3 and equilibrative nucleoside transporter 2 in the resistance of T-lymphoblastic cell lines to thiopurines. Biochem Biophys Res Commun. 2006;343:208-15.

134. CAR-T CD19 for Acute Myelogenous Leukemia With t 8:21 and CD19 Expression-ClinicalTrials.gov. https://clinicaltrials.gov/ct2/show/study/ NCT04257175. Accessed 23 Aug 2020.

135. Ma G, Wang Y, Ahmed T, Zaslav AL, Hogan L, Avila C, et al. Anti-CD19 chimeric antigen receptor targeting of CD19+ acute myeloid leukemia. Leuk Res Rep. 2018;9:42-4.

136. Shah NN, Fry TJ. Mechanisms of resistance to CART cell therapy. Nat Rev Clin Oncol. 2019;16:372-85.

137. Epperly R, Gottschalk S, Velasquez MP. A bump in the road: how the hostile AML microenvironment affects CART cell therapy. Front Oncol. 2020;10:262.

138. Mardiana S, Gill S. CART cells for acute myeloid leukemia: state of the art and future directions. Front Oncol. 2020;10:697.

139. Tina E, Prenkert M, Höglund M, Paul C, Tidefelt U. Topoisomerase Ila expression in acute myeloid leukaemia cells that survive after exposure to daunorubicin or ara-C. Oncol Rep. 2009;22:1527-31.

140. Hurwitz SJ, Terashima M, Mizunuma N, Slapak CA. Vesicular anthracycline accumulation in doxorubicin-selected U-937 cells: participation of lysosomes. Blood. 1997:89:3745-54.

141. Hraběta J, Belhajová M, Šubrtová H, Rodrigo MMA, Heger Z, Eckschlager T. Drug sequestration in lysosomes as one of the mechanisms of chemoresistance of cancer cells and the possibilities of its inhibition. Int J Mol Sci. 2020;21:4392.

142. Circu M, Cardelli J, Barr M, O'Byrne K, Mills G, El-Osta H. Modulating lysosomal function through lysosome membrane permeabilization or autophagy suppression restores sensitivity to cisplatin in refractory non-small-cell lung cancer cells. PLoS One. 2017;12:e0184922.

143. Groth-Pedersen L, Ostenfeld MS, Høyer-Hansen M, Nylandsted J, Jäättelä M. Vincristine induces dramatic lysosomal changes and sensitizes cancer cells to lysosome-destabilizing siramesine. Cancer Res. 2007;67:2217-25.

144. Patel C, Stenke L, Varma S, Lindberg ML, Björkholm M, Sjöberg J, et al. Multidrug resistance in relapsed acute myeloid leukemia: evidence of biological heterogeneity. Cancer. 2013;119:3076-83.

\section{Publisher's Note}

Springer Nature remains neutral with regard to jurisdictional claims in published maps and institutional affiliations. 